\title{
FUTURO DO MERCADO FINANCEIRO NACIONAL: MOMENTO DE INOVAÇÃO PELAS FINTECHS EM TRANSFORMAÇÃO AO AMBIENTE BANCÁRIO NACIONAL
}

\section{ARTIGO ORIGINAL}

FELIPPE, Gibran ${ }^{1}$, ZOTES, Luís Pérez²

FELIPPE, Gibran. ZOTES, Luís Pérez. Futuro do mercado financeiro nacional: momento de inovação pelas FinTechs em transformação ao ambiente bancário nacional. Revista Científica Multidisciplinar Núcleo do Conhecimento. Ano 05, Ed. 10, Vol. 07, pp. 31-62. Outubro de 2020. ISSN: 2448-0959, Link de acesso: https://www.nucleodoconhecimento.com.br/contabilidade/mercado-financeiro, DOI: 10.32749/nucleodoconhecimento.com.br/contabilidade/mercado-financeiro

\section{RESUMO}

O sistema bancário brasileiro se encontra em um estágio de maturidade propício para o recebimento de um novo entrante que, seguindo a tendência mundial, são as FinTechs[3]. Dessa forma, estas empresas que utilizam a tecnologia para fornecer serviços financeiros, estão começando a impactar o mercado financeiro nacional, trazendo consigo potencial para abalar o resultado das grandes corporações financeiras do país. No presente artigo, tem-se um amplo panorama da concentração do mercado bancário nacional, comparativamente aos padrões globais, bem como o dimensionamento da oportunidade para novos entrantes por meio de tecnologias estabelecidas por startups[4], num processo irreversível em termos de inovação. A metodologia, aqui utilizada, baseou-se numa ampla revisão de literatura tendo como resultado a identificação e as consequências dos principais impactos dessa nova ordem financeira, na qual o tamanho deixa de ser tão relevante, frente à implementação de novas práticas para um espectro de clientes em constante renovação. Os novos entrantes no mercado financeiro deverão ser verdadeiramente

\footnotetext{
${ }^{1}$ Mestrado Profissional em Sistemas de Gestão.

${ }^{2}$ Doutorado em Engenharia de Produção. Mestrado em Engenharia Civil. Graduação em Engenharia Civil. $\mathrm{RC}: 61199$

Link de acesso: https://www.nucleodoconhecimento.com.br/contabilidade/mercado-financeiro
} 
centrados no cliente, ágeis e capazes de se adaptar a um ambiente em rápida mutação, habilidosos em trabalhar com empresas em um complexo ecossistema de parcerias e mercados. Eles deverão buscar a excelência na análise de dados, na precificação dinâmica e na construção de tecnologias que permitam que novas funcionalidades sejam desenvolvidas e implantadas. Novas necessidades, práticas, sem os símbolos de status bancário.

Palavras-chave: Inovação, FinTechs, startups, mercado bancário, tecnologia da informação.

\section{INTRODUÇÃO}

O termo FinTech pode ser amplamente definido como inovação financeira tecnologicamente habilitada, a qual pode resultar em novos modelos de negócios, aplicativos, processos ou produtos com um efeito material associado nos mercados financeiros, instituições financeiras e prestação de serviços financeiros (CARNEY, 2017). As inovações relativas à FinTech estão surgindo em muitas facetas das finanças - pagamentos de varejo e atacado, infraestruturas do mercado financeiro, gestão de investimentos, seguros, provisão de crédito e aumento de capital. Num futuro próximo, tais aplicativos poderão ser utilizados, inclusive, em operações de mercado de capitais (MOULES, 2014).

Este artigo concentra-se na evolução das FinTechs quanto ao potencial de penetração, utilização e suas consequências para o mercado financeiro nacional. Ao fazê-lo, complementa uma série de outros estudos recentemente divulgados ou sendo preparados por órgãos oficiais sobre outros aspectos das FinTechs, tendo em vistas as inúmeras discussões acerca do tema e a necessidade de regulação, por parte do BACEN, num ambiente financeiro extremamente concentrado. No Brasil, o mercado de crédito e pagamentos são as molas propulsoras até então, gerando interesse significativo entre os formuladores de políticas financeiras e do público em geral.

Ainda sob o aspecto crédito, alguns analistas sugeriram que as inovações estabelecidas pelas FinTechs poderiam transformar os mercados de empréstimos RC: 61199

Link de acesso: https://www.nucleodoconhecimento.com.br/contabilidade/mercado-financeiro 
reduzindo custos, melhorando a experiência do cliente e aprimorando as avaliações de risco de crédito. Esse aspecto não se trata apenas de uma récita, com início, meio e fim, mas simplesmente um movimento que, uma vez iniciado, tornar-se-á dinâmico e permanente, alterando definitivamente as relações bancárias tradicionais. Uma visão alternativa sustenta que o crescimento futuro do crédito das FinTechs pode ser limitado por modelos de negócios vulneráveis a mudanças nas condições financeiras (MILNE, 2016). Esse fato é relevante, uma vez que o país ainda não conseguiu criar dispositivos efetivos contra riscos de crédito.

A pergunta motivadora para o contexto presente nesse estudo é: "Por que o Brasil é diferente de outros mercados?". Embora a ruptura financeira tenha se mostrado uma tendência comum em muitos países, acredita-se que o sistema financeiro brasileiro é particularmente complexo. O mercado bancário está concentrado em relação aos padrões globais, e a penetração, pela maioria das métricas, fica abaixo dos países desenvolvidos, especialmente nas classes de renda mais baixa. Os preços dos serviços financeiros e spreads[5] para empréstimos também estão entre os mais altos do mundo.

Nessa estrutura peculiar de mercado, as empresas que almejam posicionamento, sofrem um impacto maior no Brasil do que em outros mercados desenvolvidos, ensejando diversos questionamentos, notadamente o entendimento do motivo das FinTechs tornarem-se relevantes somente agora. A resposta reside na ampliação da base tecnológica em nível mundial, alteração de perfil do mercado consumidor, além da necessidade do atendimento em escala.

Várias tendências estão convergindo, o que provavelmente aumentará a relevância das FinTechs. Outro ponto observado está nas fusões recentes, as quais concentraram ainda mais o sistema financeiro, aumentando a necessidade de novos entrantes. Smartphones e acesso à internet, mecanismos-chave de entrega para a tecnologia da informação, também estão aumentando rapidamente à medida que a geração de tecnologia avançada do Brasil atinge a maturidade. Logo, as FinTechs apresentam-se como soluções para atendimento da demanda, levandose em conta tal cenário.

RC: 61199

Link de acesso: https://www.nucleodoconhecimento.com.br/contabilidade/mercado-financeiro 
Segundo estudo recente da equipe de Equity Research[6] do banco de investimento Goldman Sachs, ficou evidenciado uma receita potencial de $R \$ 75$ bilhões em 10 anos para as mais de duzentas FinTechs, atualmente em operação no Brasil. Ainda em observação ao relatório do Goldman Sachs, pode-se notar o fraco nível de conexão mundial em termos de internet na América do Sul, frente ao continente asiático, 10,4\% anti $49,7 \%$ do total de usuários globais.

Logo, há clara necessidade de resposta por parte dos grandes bancos brasileiros, elaborando ou mesmo copiando os produtos disruptivos com necessidade de investimentos de porte e capacitação de rede em TI para maior eficiência operacional.

Os ambientes de negócios têm sofrido constantes mudanças devido à globalização e acirrada competição por espaço no mercado. A sustentabilidade e competitividade de determinada empresa (pública ou privada) depende também da qualidade de seus produtos ou serviços e do seu potencial de atendimento à demanda. Nesse ambiente, o artigo estuda a defasagem nacional, a sua necessidade de uma forte dosagem, parafraseando a medicina, de estreptomicina para rapidamente sair da letargia das grandes instituições e aumentar o potencial de inovação e diversificação dos serviços oferecidos, do contrário o lapso em termos de eficiência punirá os que não enxergaram as novas oportunidades descortinadas em outros mercados.

\section{FUNDAMENTAÇÃO TEÓRICA}

\subsection{CONJUNTURA PARA ESTABELECIMENTO DAS FINTECHS NO BRASIL}

As Fintechs, de acordo com Buchak (2017) são empresas que utilizam tecnologia para prover serviços financeiros. O surgimento das FinTechs brasileiras não seguiu na mesma velocidade observada em outros países do mundo, de fato, ainda estão começando a surgir no Brasil. Elas são estimuladas por condições cada vez mais favoráveis, o que deve torná-las progressivamente mais relevantes para os investidores com foco no setor financeiro. É possível antecipar transição, porque ela 
será diferente daquelas em mercados mais desenvolvidos e através desse ponto de partida, o próprio mercado ajustar-se-á e responderá a esse movimento.

Outra definição, amplamente aceita, para o termo FinTech está estabelecida por Carney (2017) como inovação financeira tecnologicamente habilitada, a qual pode resultar em novos modelos de negócios, aplicativos, processos ou produtos com um efeito material associado nos mercados financeiros, instituições financeiras e prestação de serviços financeiros. As inovações advindas da FinTech estão surgindo em muitas facetas das finanças, dentre as quais:

- Pagamentos de varejo e atacado;

- Infraestruturas do mercado financeiro;

- Gestão de investimentos;

- Seguros;

- Provisão de crédito;

- Aumento de capital.

Este artigo enfoca a provisão e habitação das FinTechs, não se levando em consideração, projetos ainda em andamento. Ao fazê-lo, complementa uma série de outros estudos recentemente divulgados ou sendo preparados por órgãos oficiais sobre outros aspectos das FinTechs. A tecnologia envolvida no desenvolvimento das FinTechs gerou um interesse significativo nos mercados financeiros, entre os formuladores de políticas e do público em geral. Alguns analistas sugeriram que as inovações poderiam transformar os mercados financeiros, reduzindo custos, melhorando a experiência do cliente e aprimorando as avaliações de risco de crédito e pagamentos.

Uma visão alternativa (DE ROURE, 2016) sustenta que o crescimento futuro do crédito das FinTechs pode ser limitado por modelos de negócios vulneráveis a mudanças nas condições financeiras, em decorrência de considerações sobre a proteção do consumidor e do investidor. Esse artigo delimita a visão e entendimento sobre o funcionamento dos mercados de crédito das FinTechs no Brasil, incluindo o tamanho, o escopo e o crescimento dessas atividades. Também avalia os potenciais benefícios RC: 61199

Link de acesso: https://www.nucleodoconhecimento.com.br/contabilidade/mercado-financeiro 
e riscos micro financeiros dessas atividades e considera as possíveis implicações para a estabilidade financeira no caso de o amplo de utilização desta tecnologia crescer a ponto de representar parcela significativa das operações totais no mercado financeiro nacional.

Para os propósitos deste estudo, o termo FinTech engloba toda a atividade de financeira facilitada por plataformas eletrônicas pelas quais os usuários são casados diretamente com os credores.

Quando baseadas em atividades de crédito, tais comunidades são referidas como crowdfunders[7] baseadas em empréstimos, "emprestadores peer-to-peer[8] (P2P)" ou "emprestadores de mercado". Essas plataformas eletrônicas podem facilitar uma série de transações financeiras, incluindo empréstimos garantidos e não garantidos, financiamento sem endividamento, como o financiamento de faturas, meios de pagamentos, etc. Além disso, algumas plataformas eletrônicas vão além de um modelo de negócios de correspondência P2P usando seu próprio balanço para atividades financeiras.

No Brasil, assim como em outros países do mundo, o surgimento das FinTechs não é algo simples de mensurar em termos de impacto na dinâmica usual do mercado financeiro. Os cinco maiores bancos do Brasil (excluindo os bancos de desenvolvimento) detêm $84 \%$ do total de empréstimos no sistema.

O impacto da ruptura em qualquer mercado depende, em grande parte, da forma desse mercado. No Brasil, vemos as condições em vigor para que a interrupção orientada por tecnologia tenha um impacto maior do que em alguns mercados desenvolvidos. Logo, determinadas avaliações conspícuas revelam, de forma objetiva, os seguintes pressupostos no ambiente nacional:

- O índice de concentração de mercado Herfindahl Hirschman[9] para o Brasil está na metade superior da faixa quando comparado aos mercados de outros países. Essa concentração é particularmente evidente nas agências bancárias, onde os cinco principais bancos têm $90 \%$ das agências. Com a tradicional 
distribuição de serviços financeiros sendo interrompida por novas tecnologias, derrubando barreiras à entrada;

- Penetração limitada, especialmente em baixa renda. A penetração dos serviços bancários no Brasil é baixa em comparação com os padrões globais, embora relativamente próxima dos pares na mesma região e no mesmo nível de desenvolvimento. Identifica-se barreiras à penetração decorrentes da cultura, regulação e estrutura de mercado, todas as quais poderiam ser superadas pela penetração da tecnologia e pelo envelhecimento e evolução no uso de novas ferramentas bancárias por parte da população;

- Preços caros para empréstimos, bem como outros serviços financeiros. As taxas de juros dos empréstimos no Brasil estão entre as mais altas do mundo, assim como as taxas dos serviços também são caras em comparação com as cobradas pelos bancos por serviços semelhantes em outros países com as mesmas vicissitudes. Muito desse problema reside na limitação de informações, o que aumenta o risco e reduz os incentivos para novas competições. Assim, novas tecnologias contribuem para a ampliação da tomada de preços disponíveis para clientes bancários e potenciais participantes, o que acaba levando os preços para baixo.

O impacto da ruptura em qualquer mercado depende, em grande parte, da estrutura conjuntural de forças atuantes nesse ambiente competitivo. No Brasil, observa-se as condições em vigor para que a interrupção orientada por tecnologia tenha um impacto maior do que em alguns mercados desenvolvidos. Logo, determinadas avaliações conspícuas revelam, de forma objetiva, os seguintes pressupostos no ambiente nacional: 
Figura 1 - Mapa da Revolução das FinTechs no Brasil.

\begin{tabular}{|c|c|c|c|}
\hline \multicolumn{2}{|c|}{ id="attachment_61203" } & align="aligncenter" & width="1396"] \\
\hline CONSUMER BANKING & INVESTIMENTOS & EMPRESTIMOS & NEGOCLAÇAO DE DNIDAS \\
\hline 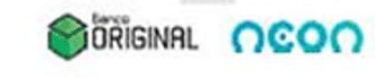 & $\boldsymbol{W}$ VÉRIOS InvesteApp & bank:acil (GERU) & - Panosim Quero Quitar! \\
\hline PAGAMENTOS & GERENCIAMENTO FINANCEIRO & CÅMBIO & SEGUROS \\
\hline 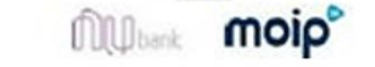 & (7) GuiaBolsa of planejel. & 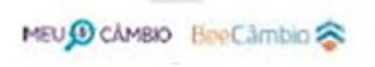 & Youse \\
\hline INCLUSAO FINANCEIRA & SOLUC̣OES PARA PME & EQUITY FINANCING & EFICIENNCIA FINANCEIRA \\
\hline 12 sinoo avante & ContaAzul qipu & (3)starmeup brcota & Fcontrol idwall \\
\hline
\end{tabular}

Fonte: ALECRIM (2019).

- Crescente penetração de smartphone e internet: número de usuários de internet no Brasil cresceu 11\% ao ano desde 2003 (em comparação com uma taxa média global de $9 \%$ ). Ao mesmo tempo, em 2015 , $86 \%$ dos adultos brasileiros possuíam um telefone celular, alta de $73 \%$ em 2010 , com $48 \%$ de todos os telefones celulares considerados smartphones, acima dos $19 \%$ em 2013. Com muitas das plataformas de tecnologia financeira usando smartphones como o método de entrega de seus serviços, a expansão contínua na penetração é contumaz;

- Bônus demográfico em expansão: a idade média da população no Brasil está aumentando, já que o bônus demográfico da década de 1990 continua a envelhecer. À medida que esta geração entra em seus anos mais produtivos e geradores de caixa, ela também deve se tornar mais frequente usuários de serviços financeiros. Ao mesmo tempo, esta geração é mais educada e mais tecnologicamente inclinada do que as gerações anteriores, o que contribui para aceitação das soluções de Fintechs baseadas na Internet e em dispositivos móveis;

- Economia em recuperação: a economia brasileira se contraiu em termos reais nos últimos três anos, mas agora está emergindo da recessão. Embora o investimento e o interesse em novas tecnologias tenham sido descontinuados durante a recessão, espera-se que esses tópicos assumam um papel mais 
proeminente à medida que a economia se recupera. Maior riqueza deve levar a mais demanda por soluções para gerenciar, intermediar e implantar riqueza.

\subsection{PRINCIPAIS OPERAÇÕES DAS FINTECHS NO BRASIL}

Observa-se no país, dia após dia, o surgimento de FinTtechs de todas as formas e tamanhos com diferentes associações. Segundo recente apresentação do Insper[10] Educacional, ministrado para funcionários da mesa de operações de uma grande tesouraria (nome da instituição resguardado em função de estratégias não autorizadas à divulgação pública) no país, existem, aproximadamente, 210 FinTechs diferentes no Brasil, o maior número da América Latina (dados de 2018). Em sua maior parte, essas empresas estão localizadas no Estado de São Paulo e operam, exclusivamente, no Brasil (Figura 1 ilustra algumas delas) embora a principal tecnologia usada seja bastante mista, assim como os clientes finais. Estima-se que essas empresas estejam atingindo uma receita total de $\mathrm{R} \$ 75$ bilhões em 10 anos, em diversos nichos de mercado.

Segundo a IAIS[11] (2017), algumas premissas são relevantes para as pesquisas de operações desta natureza num ambiente financeiro competitivo, algo plenamente factível e ajustável ao mercado nacional, dentre elas: (i) dados sobre a atividade de crédito da FinTech de estudos acadêmicos e provedores do setor privado; (ii) dados publicamente disponíveis das plataformas; (iii) estudos do setor público, acadêmico e do setor privado sobre o setor de crédito FinTech, considerado que há relevantes fontes diretamente vinculadas no trabalho existente das instituições membros de compensação e (iv) visão geral das atuais estruturas normativas e outras políticas estabelecidas para operacionalização de FinTechs.

A disponibilidade e a qualidade dos dados podem exigir maior atenção à medida que os mercados de crédito da FinTech se desenvolvem, logo importante frisar que não se trata de observação teutônica, com precisão máxima e sem desvios. Essa, provavelmente, seja a principal lacuna existente no Brasil para a devida regulação e normatização do mercado por parte da autoridade monetária. 
Em tal contexto, duas instituições apresentam-se com destaque, dentre as quais são: NuBank, uma empresa de cartão de crédito bem-sucedida que utiliza a tecnologia para identificar e capturar clientes e o Banco Original, grande pilar de operações totalmente digitais em plataformas proprietárias.

Uma das principais operações das FinTechs referem-se à atividade de crédito facilitada por plataformas eletrônicas. Isso geralmente envolve os mutuários sendo correspondidos diretamente com os investidores, embora algumas plataformas usem seu próprio balanço para emprestar (DELOITTE, 2016). As plataformas FinTech facilitam várias formas de crédito, como empréstimos a consumidores e empresas, empréstimos contra imóveis e, financiamento de dívida sem empréstimo, como o financiamento de faturas, como apresentado na tabela 1 :

Tabela 1 - Fintechs propagam-se através de vários nichos e indústrias. Identificou-se uma margem de receitas potenciais de $\mathrm{R} \$ 75$ bilhões.

\begin{tabular}{|c|c|c|c|}
\hline AREA & LÓGICA & $\begin{array}{l}\text { RECEITAS } \\
\text { POTENCIAIS } \\
\text { EM } 10 \text { ANOS } \\
\text { (R\$BILHÕES / } \\
\text { ANO) }\end{array}$ & $\begin{array}{l}\text { COMPANHIAS NO } \\
\text { BRASIL }\end{array}$ \\
\hline $\begin{array}{l}\text { Serviços } \\
\text { Bancários }\end{array}$ & $\begin{array}{l}\text { O mercado bancário } \\
\text { brasileiro é altamente } \\
\text { concentrado, o que } \\
\text { aumenta os custos e } \\
\text { limita a penetração. A } \\
\text { regulamentação e a } \\
\text { tecnologia estão } \\
\text { derrubando as barreiras à } \\
\text { entrada relacionadas à } \\
\text { distribuição, abrindo } \\
\text { caminho para novos }\end{array}$ & 50 & $\begin{array}{l}\text { Banco Original, } \\
\text { Banco Neon, } \\
\text { Zuum, Conta Um, } \\
\text { E-dinheiro }\end{array}$ \\
\hline
\end{tabular}




\begin{tabular}{|c|c|c|c|}
\hline & $\begin{array}{l}\text { entrantes que podem } \\
\text { reduzir os spreads de } \\
\text { ativos e passivos e } \\
\text { aumentar a penetração. O } \\
\text { modelo se estenderia de } \\
\text { bancos virtuais de serviço } \\
\text { completo a e-wallets } \\
\text { simples }\end{array}$ & & \\
\hline \multirow[t]{2}{*}{ Pagamentos } & $\begin{array}{l}\text { Apesar de o Brasil estar } \\
\text { em um dos mercados } \\
\text { mais desenvolvidos da } \\
\text { América Latina, o sistema } \\
\text { brasileiro de pagamentos } \\
\text { está concentrado e } \\
\text { oferece funcionalidade } \\
\text { limitada, dada a } \\
\text { tecnologia mais antiga. } \\
\text { Os novos participantes } \\
\text { aproveitam a mais } \\
\text { recente tecnologia em } \\
\text { aquisição, } \\
\text { processamento de } \\
\text { pagamentos } \\
\text { transferências } \\
\text { dinheiro, com soluções } \\
\text { nos espaços P2P e B2B. }\end{array}$ & 12 & $\begin{array}{l}\text { Stone } \\
\text { Pagamentos, } \\
\text { PicPay, Vale } \\
\text { Presente, Ta Pago, } \\
\text { PagPop }\end{array}$ \\
\hline & $\begin{array}{l}\text { Os brasileiros } \\
\text { historicamente têm } \\
\text { ferramentas limitadas } \\
\text { para administrar as } \\
\text { finanças pessoais, o que }\end{array}$ & 6 & $\begin{array}{l}\text { Guia Bolso, Quero } \\
\text { Quitar, Konkero, } \\
\text { Oganizze, } \quad \text { Quanto } \\
\text { Gastei, } \quad \text { Poupa } \\
\text { Certo, }\end{array}$ \\
\hline
\end{tabular}




\begin{tabular}{|c|c|c|c|}
\hline $\begin{array}{l}\text { Gestão de } \\
\text { Finanças } \\
\text { Pessoais }\end{array}$ & $\begin{array}{l}\text { levou a um maior uso de } \\
\text { empréstimos caros e a } \\
\text { uma baixa alocação de } \\
\text { recursos. As empresas } \\
\text { estão usando soluções } \\
\text { baseadas na Internet } \\
\text { para ajudar os usuários a } \\
\text { gerenciar contas e } \\
\text { renegociar empréstimos, } \\
\text { bem como fornecer } \\
\text { mercados para novos } \\
\text { empréstimos e produtos } \\
\text { de poupança. }\end{array}$ & & $\begin{array}{l}\text { Dinheiro, Ghaio, } \\
\text { Kitado, Acordo } \\
\text { Certo }\end{array}$ \\
\hline $\begin{array}{l}\text { Concessão de } \\
\text { empréstimos }\end{array}$ & $\begin{array}{l}\text { A taxa média anual de } \\
\text { empréstimos no Brasil é } \\
\text { de } 32 \% \text {, mas pode chegar } \\
\text { a } 15 \% \text { ao mês para certos } \\
\text { empréstimos pessoais. } \\
\text { Parte disso pela } \\
\text { impulsionada de } \\
\text { quantidade limitada de } \\
\text { informações } \\
\text { mutuários e mutuantes } \\
\text { têm uns sobre os outros, } \\
\text { bem como por } \\
\text { deficiências } \\
\text { distribuição. As empresas } \\
\text { estão usando plataformas } \\
\text { baseadas na Internet e } \\
\text { em dispositivos móveis, } \\
\text { juntamente com modelos }\end{array}$ & 22 & $\begin{array}{l}\text { NuBank, Geru, } \\
\text { Nexoos, } \\
\text { Credisphera, BKF } \\
\text { Online }\end{array}$ \\
\hline
\end{tabular}




\begin{tabular}{|c|c|c|c|}
\hline & $\begin{array}{l}\text { de negócios inovadores, } \\
\text { para preencher a lacuna } \\
\text { entre poupadores e } \\
\text { tomadores de } \\
\text { empréstimos, dentro e } \\
\text { fora do sistema } \\
\text { financeiro. }\end{array}$ & & \\
\hline $\begin{array}{l}\text { Investimentos, } \\
\text { Economia, } \\
\text { Gestão de } \\
\text { Patrimônios, } \\
\text { Negociação }\end{array}$ & $\begin{array}{l}\text { Poupar dinheiro no Brasil, } \\
\text { particularmente para os } \\
\text { estratos de renda mais } \\
\text { baixa, tem sido deixado } \\
\text { para os produtos } \\
\text { bancários de varejo com } \\
\text { baixos rendimentos, } \\
\text { resultado de limitações na } \\
\text { distribuição e informação, } \\
\text { bem como concentração } \\
\text { de mercado. Por meio de } \\
\text { plataformas on-line de } \\
\text { fácil utilização, novas } \\
\text { empresas oferecem aos } \\
\text { clientes alternativas para } \\
\text { investir em produtos de } \\
\text { renda fixa e capital, direta } \\
\text { ou indiretamente, por } \\
\text { meio de ferramentas de } \\
\text { comparação } \\
\text { destacam as vantagens e } \\
\text { desvantagens de cada } \\
\text { produto. }\end{array}$ & 10 & $\begin{array}{l}\text { Magnetis, Órama, } \\
\text { SmartBrain, } \\
\text { Investeapp, Verios, } \\
\text { SmarttBot, Warren, } \\
\text { Easynvest, Yubb, } \\
\text { Renda Fixa, Meus } \\
\text { Ynvestimentos, } \\
\text { controlAção }\end{array}$ \\
\hline
\end{tabular}




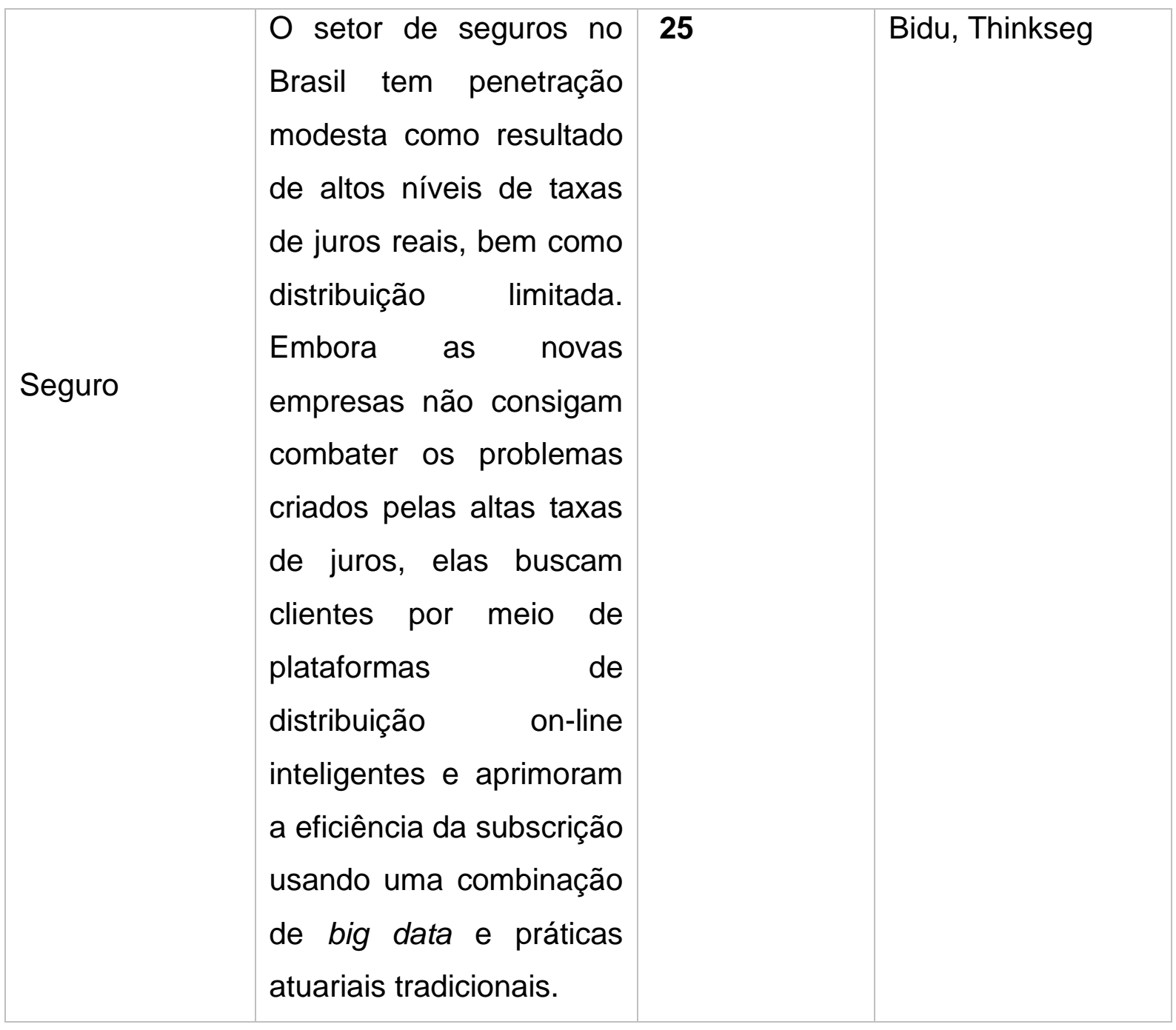

Fonte: BANCO GOLDMAN SACHS (2017).

Também há variação na base de credores das plataformas de crédito da FinTech: algumas fontes de financiamento são principalmente de investidores de varejo, enquanto outras usam recursos significativos de investidores institucionais, bancos e mercados de securitização. Os bancos originam empréstimos para plataformas de crédito da FinTech em várias jurisdições. A disponibilidade de dados oficiais sobre o crédito da FinTech é limitada, portanto, a maioria das análises desses mercados baseia-se em pesquisas setoriais não oficiais e em divulgações financeiras de plataformas.

Pesquisas acadêmicas sobre volumes de empréstimos em 2015 mostram considerável dispersão no tamanho do mercado de crédito da FinTech em todas as RC: 61199

Link de acesso: https://www.nucleodoconhecimento.com.br/contabilidade/mercado-financeiro 
jurisdições, inclusive no mercado incipiente nacional. Em termos absolutos, o maior mercado de crédito da FinTech é a China, seguido à distância pelos Estados Unidos e pelo Reino Unido (em relação à China, tal mercado merece um foco especial, a ser discorrido no próximo tópico).

Em geral, o crédito da FinTech é uma pequena fração do crédito geral, mas parece estar crescendo rapidamente e pode ter participações muito maiores em segmentos de mercado específicos. Por exemplo, no Reino Unido, o crédito da FinTech foi estimado em $14 \%$ dos fluxos equivalentes de empréstimos bancários brutos para pequenas empresas em 2015, mas apenas $1,4 \%$ do estoque em aberto de crédito bancário para consumidores e pequenas empresas e médias empresas a partir do final de 2016. Em relação aos bancos tradicionais, a forte digitalização de processos e foco especializado das plataformas de crédito FinTech pode reduzir os custos de transação e trazer conveniência para os usuários finais. Pode também aumentar o acesso a crédito e investimentos para segmentos carentes da população ou do setor empresarial. Não obstante esses benefícios, há uma série de vulnerabilidades potenciais que podem impedir $\mathrm{o}$ crescimento futuro do setor. $O$ desempenho financeiro das plataformas poderia ser substancialmente afetado por oscilações na confiança do investidor, dados os modelos de empréstimos das agências bancárias nacionais. Outrossim, há necessidade de pareamento do tipo P2P para que operações típicas do mercado nacional possam ser transacionadas, com segurança, nas plataformas tecnológicas, ou seja, há necessidade de acesso remoto aos dados bancários, inclusive para evitar riscos operacionais em caso de ausência no limite disponível para volumes mais elevados, ou até mesmo, bloqueio para operações fraudulentas.

Além disso, o risco financeiro em plataformas pode ser maior do que nos bancos devido ao maior apetite ao risco de crédito, processos de risco não testados e exposição relativamente maior a riscos cibernéticos. Para a estabilidade financeira, a atividade de crédito da FinTech poderia apresentar uma série de benefícios e riscos, caso crescesse para representar uma parcela significativa do crédito total. 
Entre os benefícios potenciais estão o acesso a fontes de financiamento alternativas na economia. Uma menor concentração de crédito no sistema bancário tradicional poderia ser útil no caso de haver problemas idiossincráticos nos bancos. As plataformas FinTech também podem pressionar os bancos incumbentes a serem mais eficientes em sua provisão de crédito. Ao mesmo tempo, se o crédito da FinTech alcança uma parcela significativa dos mercados de crédito, isso pode gerar preocupações de risco sistêmico.

Alguns fatores que contribuem para aumentar a inclusão financeira associada ao crédito da FinTech também podem reduzir os padrões de empréstimos em países onde os mercados de crédito já são profundos. Além disso, a provisão de crédito da FinTech poderia ser relativamente pró-cíclica, levando-se em consideração o potencial de um retrocesso no crédito a certas partes da economia por causa da perda de confiança do investidor durante períodos de estresse. O gráfico 1, apresenta um panorama de custos comparativos, com destaque para a posição brasileira como uma das mais caras do planeta. 
Gráfico 1 - Custo dos empréstimos no Brasil é um dos mais altos do mundo. Taxa de empréstimo e propagação por país.

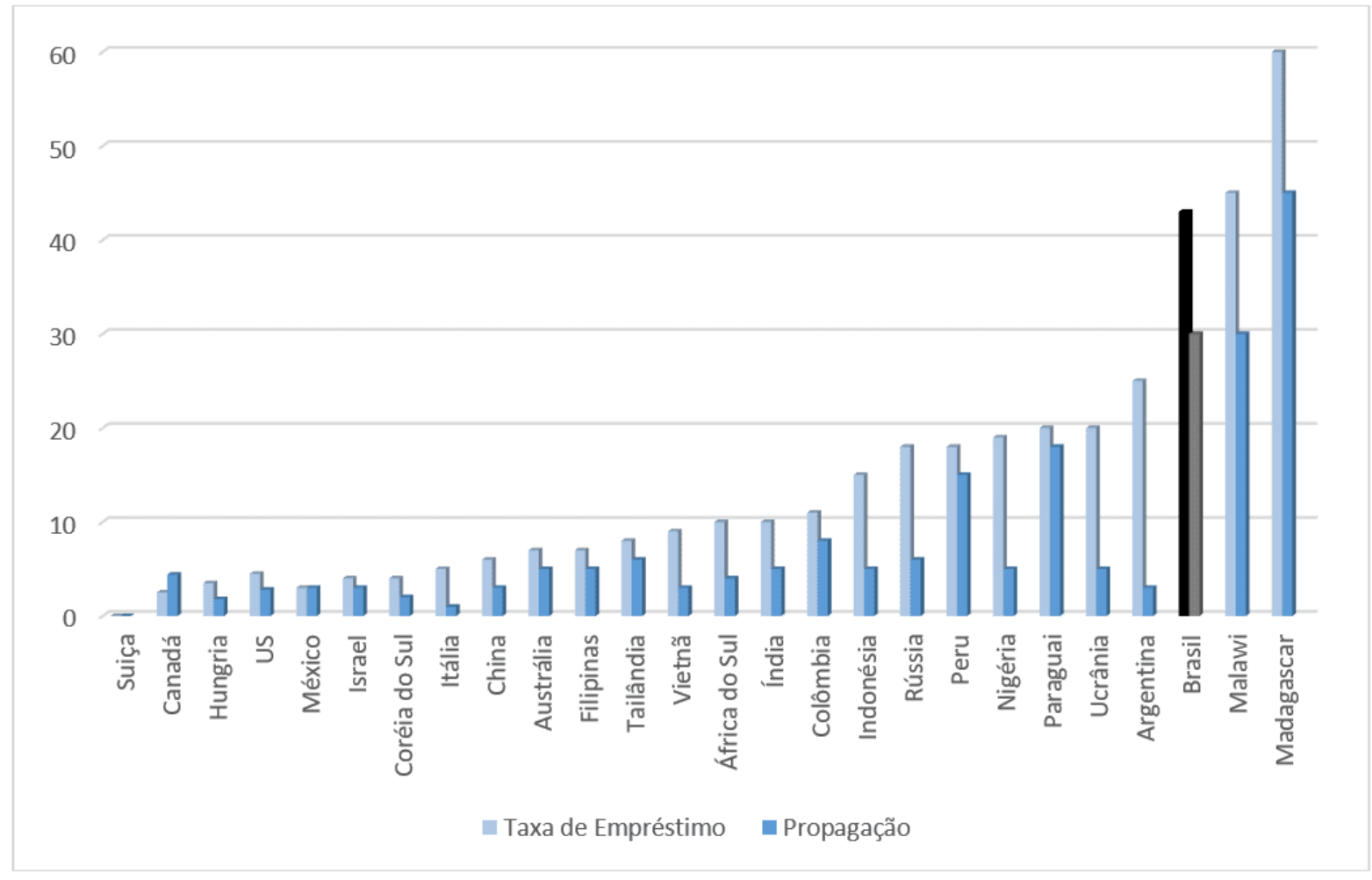

Fonte: $\operatorname{RAU}$ (2017).

Os bancos incumbentes podem assumir mais risco de crédito em resposta ao aumento da concorrência de empréstimos, enquanto uma erosão abrupta de sua lucratividade pode gerar dificuldades mais amplas para o sistema financeiro, dado o fornecimento pelos bancos de uma série de serviços sistemicamente importantes. Por fim, o crédito da FinTech coloca desafios ao perímetro regulatório e ao monitoramento pelas autoridades da atividade de crédito.

Ainda com relação ao sistema bancário nacional, tem-se os seguintes dados em maio de 2017: $90 \%$ é a porcentagem de filiais do Brasil pertencentes aos cinco principais bancos. O mercado se tornou mais concentrado desde a crise financeira: em 2007, a mesma estatística foi de $71 \%$. Já $47 \%$ é o número de agências bancárias por 100.000 adultos em 2015, tornando o Brasil um dos sistemas mais "ramificados" do mundo. Os galhos são bem usados, no entanto; o Brasil tem a maior parcela da população 
relatando que vai a uma agência física mais de cinco vezes por trimestre. $50 \%$ é participação das despesas administrativas bancárias relacionadas às operações das agências.

Acerca do potencial do mercado tem-se que: $50 \%$ contra $12 \%$ é taxa de juros que os bancos brasileiros cobram sobre empréstimos, versus a taxa que oferecem aos depositantes da poupança. O spread de empréstimos, que sinaliza um alto custo de empréstimos e alto custo de oportunidade de poupança, é maior apenas no Malawi e em Madagascar, segundo relatório do Goldman Sachs (2017). Além desses aspectos $57 \%$ é a parcela do total de empréstimos que os bancos brasileiros de propriedade do governo mantinham em seu pico (julho de 2016). Esse crescimento das ações pressionou os níveis de capital, que são mais baixos nos bancos do governo do que nas instituições privadas.

As FinTechs, de uma forma ou de outra, existiram no Brasil durante grande parte dos últimos 10 anos. Como mencionado nos tópicos anteriores, algumas das condições do mercado brasileiro, em particular a forte concentração de serviços bancários e outros serviços financeiros nas mãos de um pequeno número de empresas, criam um ambiente favorável para a interrupção, mas elas também existem há algum tempo.

Nos últimos anos, outros fatores mudaram, o que vemos como a criação de um ambiente mais receptivo para a interrupção. Primeiro, a concentração no sistema bancário aumentou. Em segundo lugar, a penetração da tecnologia, em especial dos smartphones, aumentou ao ponto em que os modelos de negócios de várias das FinTechs podem atingir massa crítica, beneficiando-se também de dados demográficos mais abertos à mudança. Terceiro, a desaceleração do ciclo econômico e a recuperação esperada nos próximos anos poderiam criar a oportunidade para novas empresas emergirem e crescerem com a atividade econômica. Conforme apresentado no gráfico 2, as taxas de manutenção de contas no Brasil são superiores às de outros países. 
Gráfico 2 - Taxa mensal de manutenção de conta / GDP per capita 2015-2016.

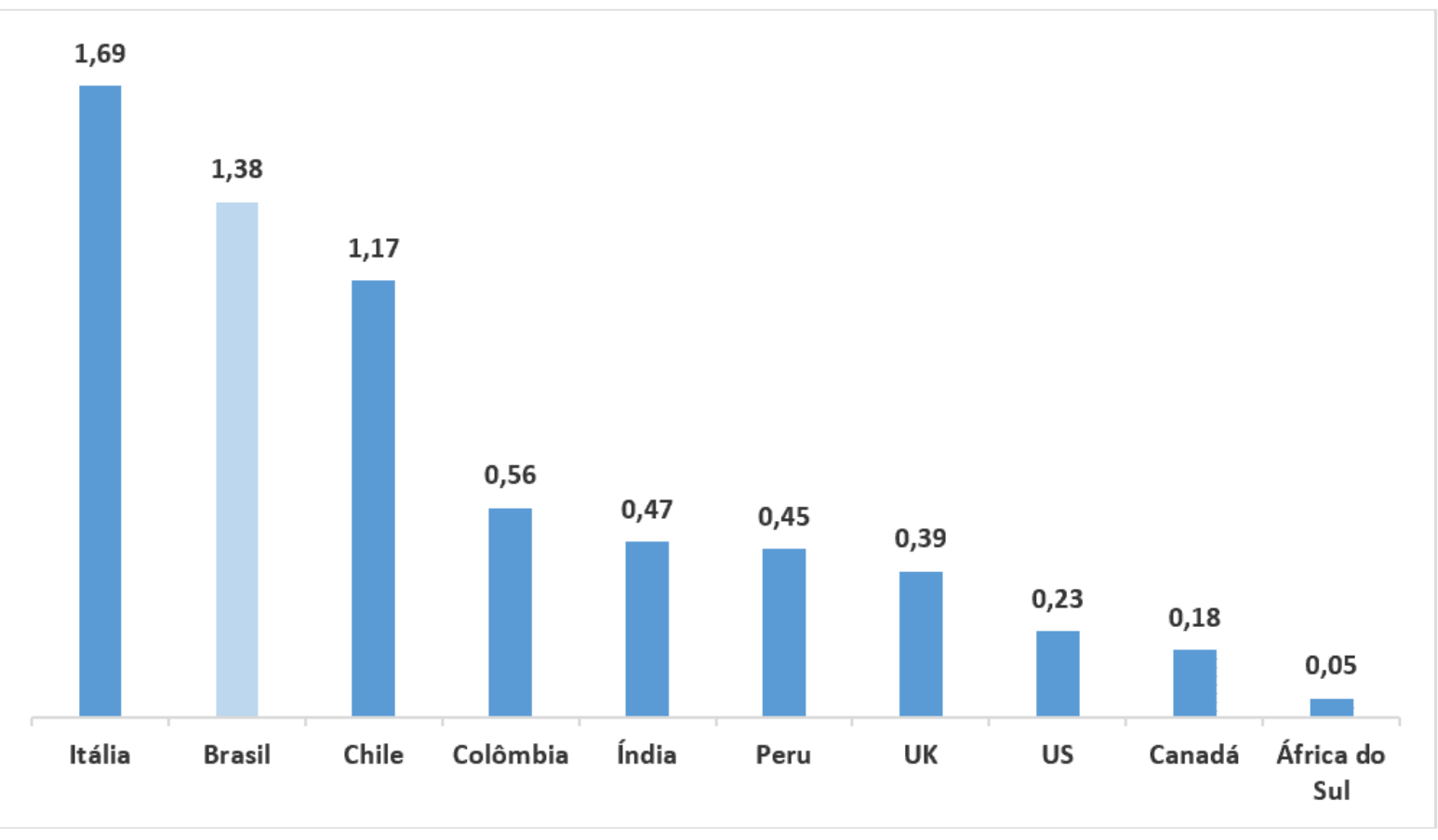

Fonte: $\operatorname{RAU}(2017)$.

Existem razões específicas para as taxas e spreads no Brasil serem maiores. Muito tem que ser feito, como mencionado acima, dado regulamentação e impostos (particularmente o último), mas outros tem a ver com a informação ou a falta dela.

O Brasil tem uma agência de crédito negativa (que identifica o mau comportamento dos não pagadores, mas não segue o bom comportamento dos pagadores), mas os esforços para desenvolver um departamento de crédito positivo (o que reduziria os riscos e spreads) foram misturados até agora.

Nenhuma informação é compartilhada com os participantes em potencial, o que limita a concorrência, diminuindo a visibilidade dos retornos potenciais. O governo está pressionando os bancos para reduzir os spreads, mas é possível que a concorrência - decorrente de avanços tecnológicos disruptivos que melhorem o fluxo de informações, provavelmente, teria mais sucesso. 
Em termo de utilização de internet e smartphones, observa-se que o movimento ainda é de ascensão, pois o uso da internet no Brasil tem aumentado na maior parte da última década (o número de usuários tem crescido 11\% desde 2005), em grande parte em linha com as tendências globais (CAGR[12] de 9\% desde 2005).

O número de usuários da internet está acima da média global, conforme dados do Banco Mundial, enquanto o uso de banda larga para conexão com a internet parece estar alinhado com a média. De acordo com a agência brasileira de geografia e estatística, o IBGE, o uso da internet é maior nos níveis de renda mais altos do que nos de renda mais baixa e mais prevalente entre os indivíduos com mais anos de estudo e entre 15 e 34 anos, considerando uso da internet através de uma combinação de computadores desktop, telefones celulares e tablets.

A penetração de telefones celulares no Brasil é relativamente alta, com mais celulares per capita do que nos Estados Unidos ou no Reino Unido, de acordo com o Banco Mundial. O Pew Research Center observou que, em 2015, 86\% dos adultos brasileiros tinham um telefone celular, em comparação com uma média de $86 \%$ em 39 países pesquisados (e acima de $73 \%$ em 2010).

Ainda de acordo com o Pew Research Center, $48 \%$ de todos os celulares no Brasil a partir de 2015 foram considerados smartphones, ante 19\% em 2013. Esse nível de penetração dos smartphones está em linha com a média global, mas fica aquém dos níveis em mercados desenvolvidos. Também em termos de distribuição de renda, fica notória a disparidade de custos de operações dos bancos brasileiros para os clientes, conforme o gráfico 3 . 
Gráfico 3 - Taxas bancárias de AVG / rendimento disponível per capita X Coeficientes GNI.

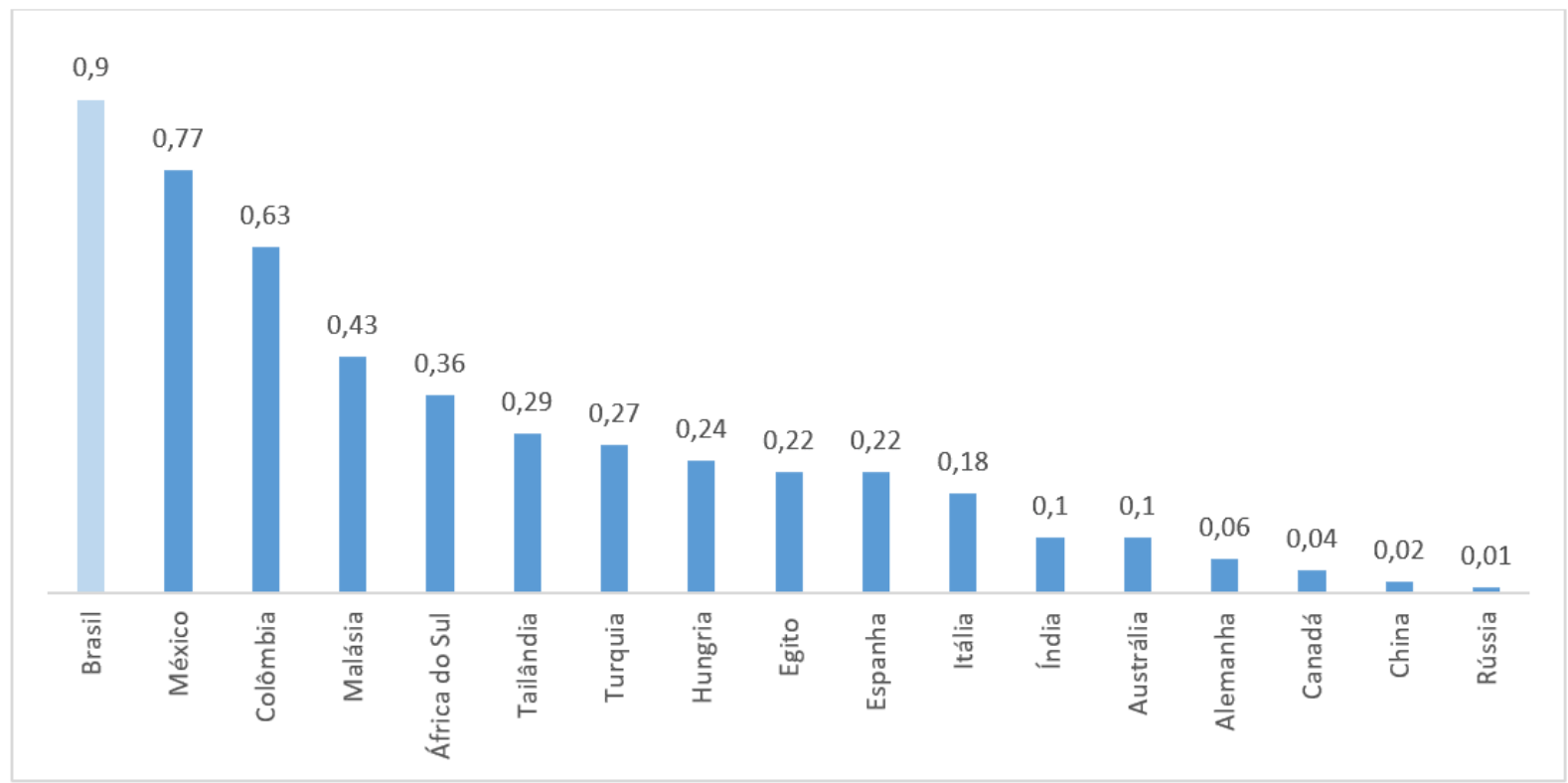

Fonte: $R A U$ (2017).

No ambiente nacional também se examina os segmentos em que há mais atividade de tecnologia financeira. Com o tempo, observa-se que as FinTechs capturam uma parte relevante do mercado de serviços financeiros, sendo um dos principais impulsionadores do crescimento e da penetração, além de um agente para reduzir spreads e taxas. Dada a dinâmica do mercado brasileiro (concentração, penetração e preço), tal evolução vem acontecendo de forma diferente do que ocorreu em outros mercados, tanto desenvolvidos quanto em desenvolvimento. Assim, a ascensão das FinTechs, provavelmente, estimulará os bancos incumbentes a investir pesadamente em TI, reduzindo custos e melhorando a eficiência.

\subsection{ANÁLISE DO BENCHMARKING CHINÊS}

Antes de analisar, propriamente, o mercado chinês, torna-se importante listar algumas características relevantes daquele país, bem como o motivo dessa análise, fundamentada na correlação direta com o Brasil, uma vez que os mercados financeiros internacionais, historicamente, consideram Brasil e China como países emergentes e pares, todavia, conforme abordado por recente relatório da revista The RC: 61199

Link de acesso: https://www.nucleodoconhecimento.com.br/contabilidade/mercado-financeiro 
Economist, a China distanciou-se do Brasil rumo aos países desenvolvidos, em que, muito desse aspecto reside exatamente no ganho tecnológico dos últimos anos.

Segundo a Internet World Stats (2017), tem-se como dados relevantes para a China, a qual é a segunda maior economia do mundo:

- Extensão territorial: $9.597 .000 \mathrm{~km}^{2}-3^{\mathrm{a}}$ maior do mundo;

- População: 1,379 bilhão de habitantes - país mais populoso do mundo;

- Número de usuários da Internet: 705 milhões de pessoas (triplo da quantidade de usuários ativos dos EUA, cerca de 242 milhões de pessoas);

- Em 2015 a China arrecadou US\$ 231 bilhões em fundos de riscos, ultrapassando os EUA em montante total de capital de risco investido;

- Os investidores colocaram US\$19,3 bilhões em empresas asiáticas versus US \$ 18,4 bilhões em empresas americanas no segundo trimestre deste ano;

- Quase $15 \%$ da população adulta na China está engajada de alguma forma com empreendedorismo e $11 \%$ desse grupo já gerencia um negócio estabelecido;

- Em 2015, 12\% dos universitários formados da Universidade de Pequim abriram ou trabalharam em startups. Em 2005, esse número era apenas 4\%;

- A China é o país que mais tem avançado no ranking global de inovação e, isso se deve ao crescente investimento em pesquisa e expansão do número de patentes. 
Gráfico 4 - Patentes x P\&D.

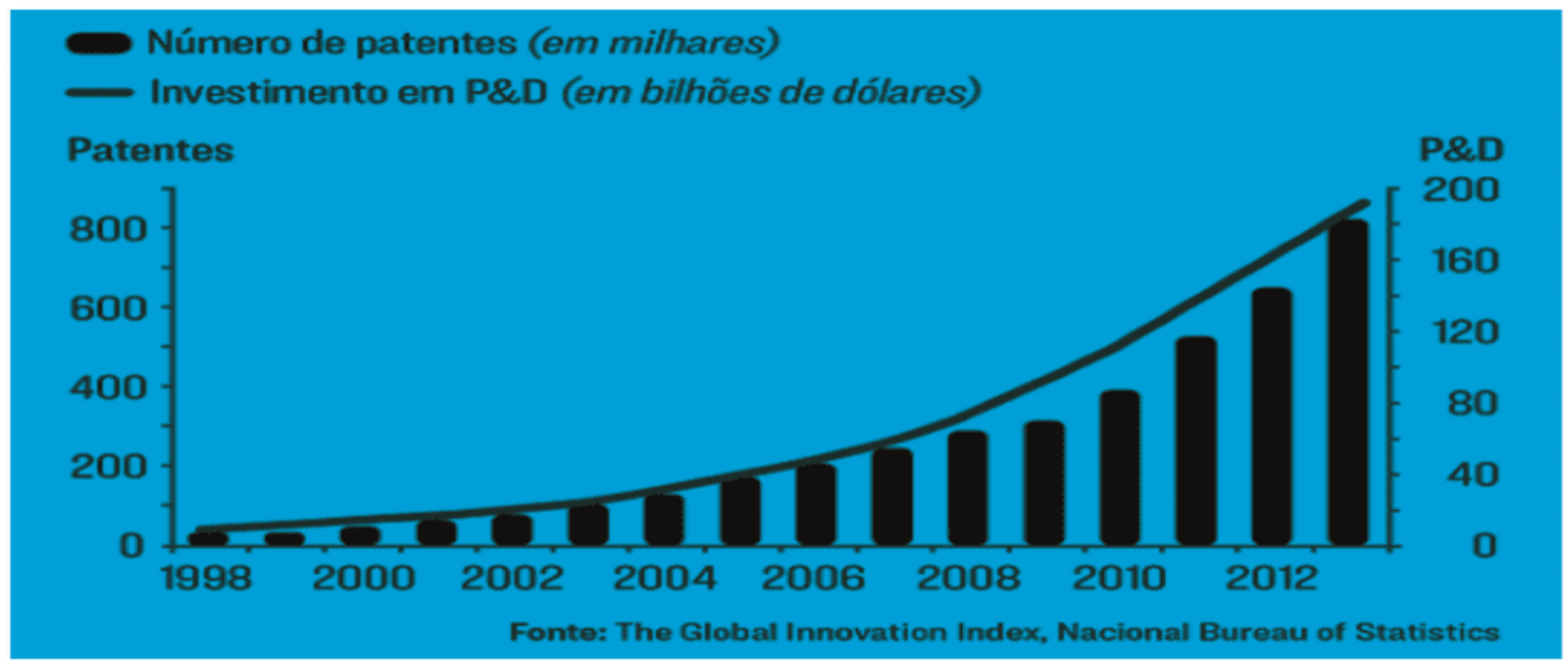

Fonte: RATINECAS (2019).

Assim como o Vale do Silício nos EUA, a China também desenvolveu seu polo de tecnologia, na cidade de Beijing, assim frente ao cenário promissor do país, o engajamento vem dos dois lados: tanto da população quanto do governo chinês, que tem uma importante participação no incentivo à inovação e ao empreendedorismo.

O crescimento da classe média na China nos últimos 10 anos é sem precedentes na história da humanidade. De maior exportador do mundo, o país hoje possui a maior classe média consumista do planeta. Desde 2009 a China tornou-se o maior parceiro comercial do Brasil, desbancando a liderança dos EUA de cerca de 80 anos. O governo local atua de maneira agressiva e estratégica para fomentar negócios entre China e Brasil. O país já é o segundo com maus "unicórnios", ou seja, startups avaliadas em mais de US\$1 bilhão, e fica atrás apenas dos Estados Unidos.

Em Beijing, o governo chinês investiu, somente em 2015, cerca de US\$ 230 bilhões em startups, tendo como principais estrelas, as seguintes companhias: Lenovo, Tencent, Alibaba, Xiaomi, Meituan-Deanping, Didi-Kuadi e Baidu. Desde 1978, foram estabelecidas várias zonas econômicas especiais na China: a primeira foi na cidade de Shenzhen, e também aconteceu nos novos distritos de Pudong e Zhongguancun. 
Este último é um bairro no norte de Pequim e reúne 1 milhão de pessoas e cerca de 20 mil empresas de tecnologias. Ou seja, uma empresa de tech a cada 50 pessoas!

A comunidade de Zhongguancun tornou-se um dos principais destinos para os talentos não só da China, mas também de todo o mundo devido ao clima favorável para nascimento de startups em estágio inicial, concentração de talento bom desempenho na produção e custo de vida acessível.

Não há consenso se o Vale do Silício Chinês fica na capital Beijing, ou em Shenzen, que fica há 50 minutos de Hong Kong de balsa, portanto cabe detalhar um pouco mais o desenvolvimento dessa região. Shenzhen gasta mais de $4 \%$ do seu PIB em pesquisa e desenvolvimento, o dobro da média do continente e, em Nanshan, o número é superior a $6 \%$. A maior parte desse investimento vem de empresas privadas. As empresas em Shenzhen classificam mais patentes internacionais do que na França ou Grã-Bretanha.

Em apenas dois anos, o empreendedorismo chinês transformou-se em uma tendência e o país reconheceu que essa iniciativa acelera o emprego, gera riqueza e suaviza pressões financeiras. No final de 2016, novas políticas públicas foram divulgadas com objetivo de fomentar essa onda de empreendedorismo. Alguns exemplos são:

- Estabelecimento de isenções de tributos a empresas que criam novas tecnologias com objetivo de estimular o desenvolvimento e a pesquisa;

- Publicação de novas regras para eliminar barreiras na compra e venda de tecnologia que até 2015 precisava de autorização de dois ministérios diferentes;

- Investimentos em estrutura, logística e apoio ao emprego no setor de tecnologia;

- Implementação de internet em locais remotos.

O caso chinês é emblemático como proxy para o Brasil, pois fica notório o distanciamento da realidade nacional, nos últimos anos, frente ao enorme avanço de inovação do gigante asiático, algo que de fato altera a dinâmica do sistema financeiro, 
o qual deixa de atender apenas o empreendedor condestável, selecionado pelo Estado, mas generaliza o volume de investimentos pautado em bons projetos.

Segundo um relatório do Centro de Informações da Internet da China, dos 700 milhões de usuários da internet, 557 milhões deles fazem o uso de smartphones para ficar online e $72,1 \%$ dos chineses que utilizam a internet tem de 10 a 39 anos, afirma o China Internet Report, 2017.

Quanto aos hábitos dos usuários de internet chineses, houve um aumento de $20 \%$ no percentual de compras on-line em relação a 2014. Com tudo isso, as vendas do varejo online da China estão crescendo $30 \%$ ao ano e o volume de pagamentos móveis atingiu quase quatro vezes o valor do ano passado, chegando a US\$ 8,6 trilhões.

De 2014 a 2016, os fundos de capital de risco investiram US\$ 77 bilhões em startups chinesas, seis vezes mais do que nos três anos anteriores. Segundo o relatório China Startup Outlook 2017, as startups chinesas acreditam que os fundos de venture capital e o investimento privado são as melhores fontes de capital.

De acordo com a CBI Insights, as quatro maiores empresas de internet da China investiram US\$ 5,6 bilhões em 48 negócios de tecnologia dos EUA nos últimos dois anos. Atualmente, segundo um estudo da McKinsey, o país está entre os três principais destinos globais de investimento em tecnologias inovadoras.

Em termos de FinTechs, a China é líder mundial e de longe o maior mercado de pagamentos digitais, representando quase metade do total global. No setor de empréstimos on-line, o país ocupa três quartos do mercado global. O volume de pagamentos móveis atingiu quase quatro vezes o valor do ano passado, chegando a US\$ 8,6 trilhões, em comparação com apenas US\$ 112 bilhões nos EUA.

Em 2016, o investimento em empreendimentos de finanças na China totalizou US\$ 10,2 bilhões e superou os US\$ 9,2 bilhões da América do Norte. Quatro das cinco FinTechs mais inovadoras do mundo são chinesas. A maior delas, a Ant Financial, foi avaliada em cerca de US\$ 60 bilhões, em parceria com o UBS, maior banco da Suíça. 
A figura 2 apresenta alguns dos principais "unicórnios" chineses:

Figura 2 - Principais "unicórnios" chineses.

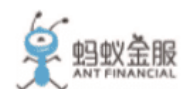

Ant Financial

A Ant Financial é a fintech com maior valor no pais, estimada em US\$ 60 bilhōes. A empresa opera várias marcas e produtos. incluindo a principal plataforma de pagamento on-line da China Alipay.

\section{回百融金服 \\ 100 Credit}

A 100 Credit é um provedor de serviços de crédito da Internet que utiliza Big Data para avaliar as classificaçōes de crédito individuais e ajudar os credores a avaliar o risco e monitorar os empréstimos existentes por potenciais inadimplências.

\section{陆呈所}

Lufax.com

$\frac{\text { Lufax }}{\text { A Lufax é a segunda startup de }}$
finanças privadas mais valiosa
da China. com uma avaliaçāo de
US\$ 18.5 bilhōes. Ela é um mer-
cado online de financiamento na
Internet e o segundo maior cre-
dor peer-to-peer na China.

大众点评

dionping.com

\section{China Internet Plus Holding}

A China Internet Plus Holding é uma empresa de comércio eletrônico avaliada em US\$ 18 bilhōes. O grupo desenvolve e opera um site de comércio social, que oferece descontos para cinemas, restaurantes $e$ até setor de saúde.

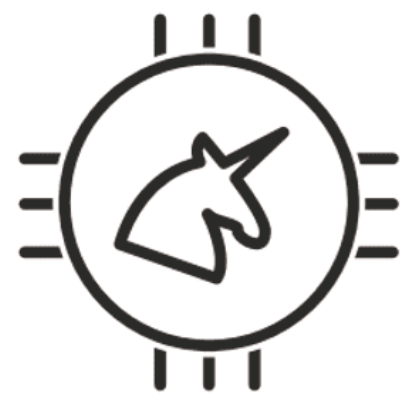

Fonte: STARTSE (2018).

\subsection{PLANO DE MUDANÇA ESTRUTURAL PARA O AMBIENTE FINANCEIRO NACIONAL}

Como as FinTechs no Brasil começam a ganhar participação de mercado em cada um de seus respectivos mercados, bem como a abrir alguns novos mercados ainda inexplorados, espera-se que os bancos brasileiros reajam. Essa reação pode vir de várias maneiras, sendo que a mais visível é imitar os produtos e serviços lançados pelas FinTechs. A reação será mais forte na proporção do impacto, onde entende-se que o maior risco de perda de participação vincula-se ao surgimento dos bancos virtuais. Esse tipo de negócio representa a mola propulsora de aceleração no que tange a migração de tijolos para cliques e, como tal, validam as mudanças trazidas pelas FinTechs. O resultado final, através de uma rápida avaliação, é que os bancos podem perder parte do mercado (mais um fator de crescimento mais lento do que o RC: 61199

Link de acesso: https://www.nucleodoconhecimento.com.br/contabilidade/mercado-financeiro 
crescimento total) e margens (como resultado da competição), mas ambos podem ser compensados por ganhos de eficiência, custo reduzido de risco e maior penetração.

Uma das estratégias utilizadas pelos bancos para conter o fluxo de inovações e interrupções de FinTech tem sido imitar os produtos e serviços lançados. No entanto, muitas vezes os bancos adicionam seus próprios recursos aos produtos, o que às vezes muda o sucesso do produto para FinTechs.

Seguem alguns exemplos no mercado nacional:

- Digio, pelo Bradesco e pelo Banco do Brasil. Em novembro de 2016, o Bradesco e o Banco do Brasil lançaram um novo cartão de crédito chamado Digio. Trata-se de um cartão totalmente virtual, tentando replicar o modelo usado com sucesso pelo NuBank. Assim como o NuBank, todas as interações seriam feitas via celular, em uma plataforma simples, e não há taxa anual. No entanto, diferentemente do NuBank, não há veto de candidatos em rede, e os cartões também podem ser solicitados nas agências do Banco do Brasil e Bradesco;

- Distribuir alternativas de financiamento de terceiros. Recentemente, grandes bancos de varejo começaram a distribuir produtos de financiamento de outros bancos menores para grupos selecionados de clientes (geralmente clientes de alta renda). Esta é uma resposta à Orama e Easynvest, que oferecem vários produtos de poupança diferentes através da sua plataforma online. No entanto, os bancos cobram uma taxa mais alta na distribuição dos produtos de financiamento de outros bancos, o que torna os rendimentos menos atraentes do que os mesmos produtos oferecidos pelas FinTechs. Ao mesmo tempo, é um reflexo da grande quantidade de liquidez excedente no sistema financeiro brasileiro, em parte devido ao volume limitado de crescimento de empréstimos nos últimos anos;

- Plataformas bancárias virtuais. O Itaú Unibanco possui mais de um milhão de clientes cadastrados em sua plataforma de banco virtual. Por meio dessa plataforma, o banco interage com os clientes principalmente via internet, celular e telefone, oferecendo serviços semelhantes a filiais de forma virtual 18 horas RC: 61199

Link de acesso: https://www.nucleodoconhecimento.com.br/contabilidade/mercado-financeiro 
por dia (em oposição a seis horas de filiais). Os clientes geralmente são do nível de renda mais alto, que o banco acredita que preferiria esse novo modelo de interação. O Bradesco está considerando lançar um banco totalmente virtual, que seria separado de sua oferta regular baseada em agências, embora ainda operando dentro da mesma plataforma de TI. Os serviços seriam similares aos fornecidos pelo Banco Original ou pelo Banco Neon. No entanto, como os serviços (tanto para o novo banco online do Bradesco quanto para o banco virtual do Itaú Unibanco) ainda seriam oferecidos no âmbito de um banco de agências de varejo, eles estariam sujeitos, a nosso ver, às limitações dos processos e procedimentos estabelecidos para o banco bancário. Além disso, a cultura dos novos empreendimentos ainda seria em grande parte a dos bancos subjacentes, tornando mais difícil adotar e desenvolver uma tecnologia verdadeiramente disruptiva;

- Financiamento de FinTechs. Tanto o Itaú Unibanco (Cubo) quanto o Bradesco (InovaBRA) criaram aceleradores de tecnologia de ponta. Esses aceleradores hospedam conferências para FinTechs e muitas vezes contratar serviços das empresas em caráter temporário ou permanente.

O ambiente também vem sendo moldado a partir de investimentos por parte dos bancos diretamente em FinTechs, principalmente através de participações minoritárias. Dito isso, as FinTechs mais visíveis e bem-sucedidas (como o NuBank e o GuiaBolso) não vieram desses aceleradores.

Dessa forma, uma das principais tendências criadas para moldar o mercado bancário brasileiro nos próximos dez anos é o impulso para o banco virtual. Mesmo que os bancos não pareçam ter a cultura para realmente conduzir um processo tão disruptivo, eles adotarão novas tecnologias ao longo do tempo e isso mudará a maneira como eles interagem com os clientes, entregam e precificam os novos produtos, gerenciam seu impacto físico e implantam sua capital. As áreas claras para melhor desempenho vêm, a nosso ver, da eficiência operacional melhorada, melhores práticas de subscrição de empréstimos e maior penetração de serviços financeiros. 
Além do fechamento de agências os bancos buscam constantemente melhorias na eficiência operacional, mas, como mencionado acima, esse processo se intensificou nos últimos anos. Isso se deu em grande parte na forma de fechamento de filiais e racionalização de funcionários. Mas como a economia brasileira passou por uma longa e profunda recessão nos últimos três anos, é difícil separar os ajustes feitos por razões cíclicas (a recessão) daqueles feitos por razões estruturais (a natureza cambiante do setor bancário). Dito isso, necessitar-se monitorar a força de tais ajustes nos próximos dois a três anos, levando a investimentos mais significativos em $\mathrm{Tl}$, mais fechamentos de agências e reduções no número de funcionários. Os gráficos 6 e 7 ilustram as transações digitais e bancárias:

Gráfico 6 - Transações digitais (internet e mobile) tornaram-se cada vez mais relevantes para os bancos nos últimos anos. \% de transacções efetuadas através de plataformas internet/móveis.

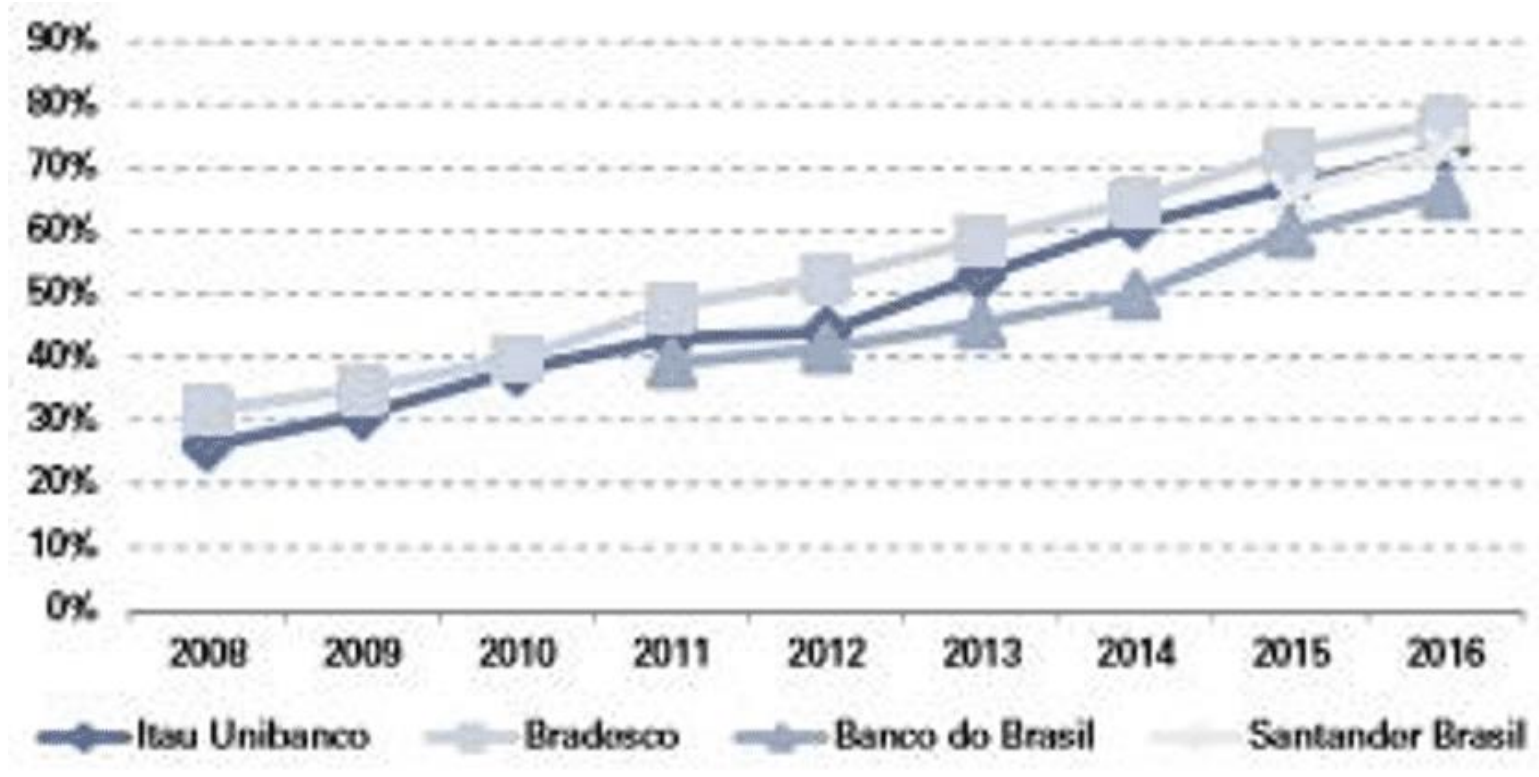

Fonte: BACEN (2018).

Gráfico 7 - Cerca de três quartos de todas as transações bancárias nos principais bancos brasileiros são digitais. Detalhamento de transações, Bradesco, Itaú Unibanco, Banco do Brasil. 


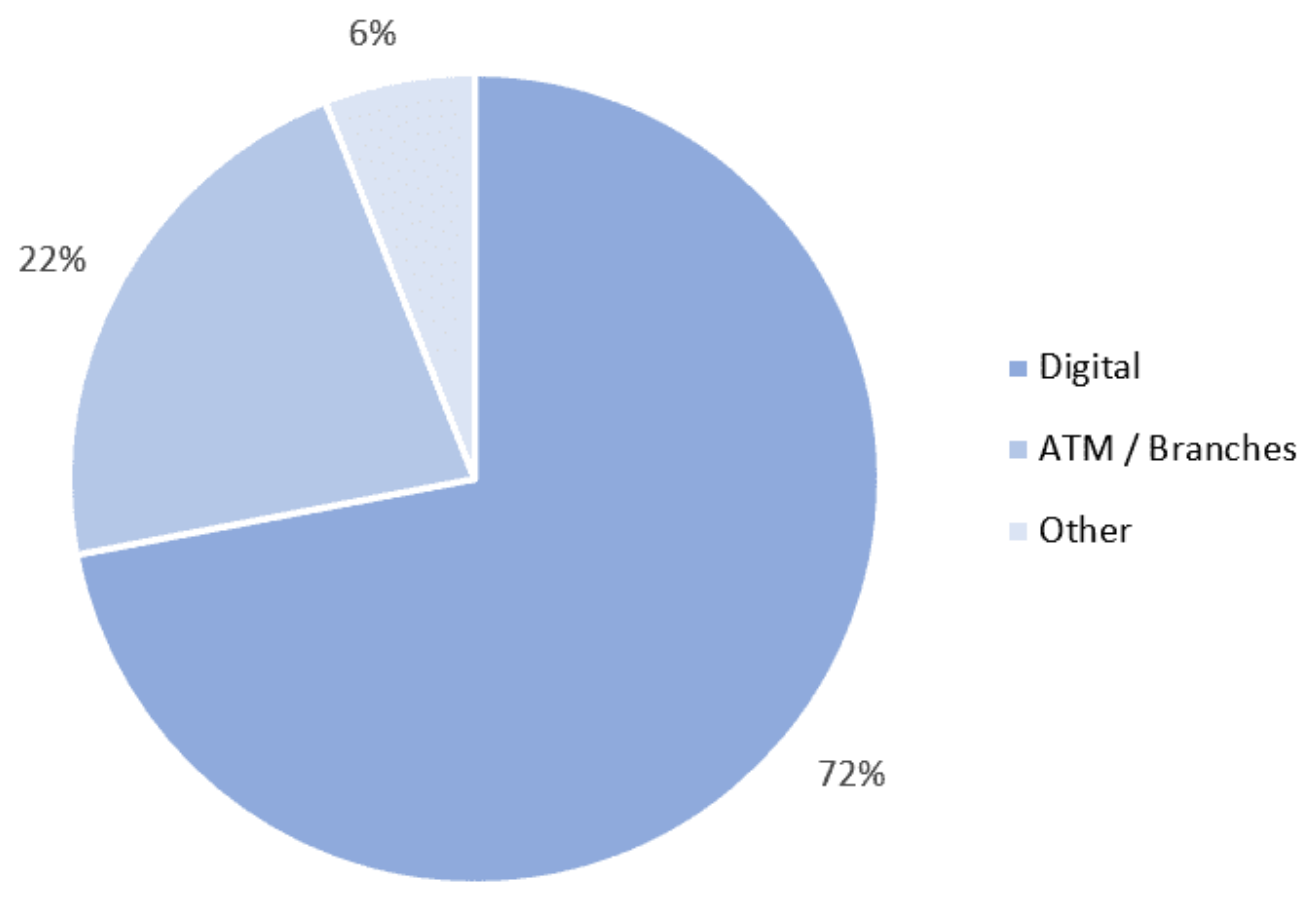

Fonte: BACEN (2018).

Como ganhos de informação apoiam melhor o apreçamento de empréstimos, mm modelo virtual, provavelmente, dará aos bancos mais pontos de contato com os clientes e, como resultado, mais informações com as quais os bancos podem tomar suas decisões. Por exemplo, no momento em que o Brasil opera essencialmente um departamento de crédito negativo (embora um modelo mais robusto para o departamento de crédito positivo esteja em processo de aprovação no Congresso), as informações sobre os tomadores de empréstimo são limitadas.

Os bancos são obrigados a confiar em análises estatísticas das informações fornecidas pelos mutuários, o que aumenta as chances de erros do tipo I e do tipo II (Erros inferenciais em testes de hipótese para maior controle da significância amostral dos resultados).

De acordo com Moules (2014), uma experiência bancária online geraria significativamente mais dados que os bancos podem usar para determinar o risco de 
crédito para os tomadores de varejo, que, quando combinados com o poder da análise big data[13], poderiam ajudar os bancos a conceder empréstimos aos devedores certos na hora certa.

Mesmo que um departamento de crédito positivo mais robusto não estivesse em desenvolvimento, a tecnologia e o big data poderiam, em parte, imitar sua função. Pesquisas acadêmicas mostram que agências de crédito positivas, ao substituir as agências de crédito negativas, aumentam a quantidade de empréstimos e reduzem o custo do risco, o que se traduz em spreads menores. A combinação desses fatores teria um impacto positivo nos resultados bancários.

Uma migração para o banco digital exigiria uma mudança na cultura bancária no Brasil, bem como na maneira como os bancos tratam seus clientes. Mas, ao mesmo tempo, poderia servir para atrair mais clientes para o sistema financeiro. Como o setor bancário é normalmente visto como um inconveniente necessário, especialmente entre os clientes mais jovens, contornar a agência e oferecer produtos e serviços diretamente aos clientes por meio de aplicativos móveis ou baseados na web pode aumentar sua penetração e vendas.

Seria mais fácil separar serviços e produtos e, como resultado, cobrar taxas sob medida, atraindo partes da população, particularmente nos segmentos de renda mais baixa, que atualmente não fazem parte do sistema financeiro. Embora uma parte substancial desses novos clientes possa ser capturada por FinTechs, os bancos também devem se beneficiar de maiores níveis de atividade financeira e, até certo ponto, fluxo adicional dos clientes.

\section{METODOLOGIA}

A metodologia do presente artigo, de natureza quantitativa, busca apresentar resultados quantificados através da coleta de dados sem a utilização de meios formais. O trabalho iniciou-se na elaboração de um relatório de mercado com a coleta de dados originária do Banco Goldman Sachs (2017), sobre as profundas e necessárias mudanças, as quais o ambiente financeiro sofrerá em um futuro próximo. 
Através da pesquisa exploratória que procura averiguar algo em um organismo, ou, em um determinado fenômeno para melhor compreender e com maior precisão (VERGARA, 2011), buscou-se constatar os conceitos sobre a inovação bancária, transformação digital, experiência do cliente, modelos disruptivos, finanças pessoais, ambiente regulatório e, entre outros aspectos.

O desenvolvimento da pesquisa se deu por meio do levantamento bibliográfico e revisão de literatura de materiais já desenvolvidos sobre o assunto (GIL, 2010). Sendo assim, foi possível vir a entender a dinâmica da evolução relativa ao surgimento das startups financeiras, bem como, suas formas de atuação através das FinTechs.

A coleta de informações nas bases de dados, se deu por meio da utilização do modelo booleano, em que um documento é representado por um composto de termos indexados, podendo ser definidos de duas formas: manual ou por meio de algoritmos computacionais (UNESP, 2018). Através do modelo booleano foi realizada a coleta de informações para elaboração do presente artigo, utilizou-se termos compostos por conteúdos ligados por operadores lógicos: AND, OR e NOT, em que foram obtidos como resultado da pesquisa, conteúdos relacionados ao ambiente financeiro.

\section{CONSIDERAÇÕES FINAIS}

Independentemente do posicionamento estratégico do país no contexto de um novo modelo de negócios financeiros, é notório que empresas bem-sucedidas terão algumas características comuns. O objetivo do presente artigo reside em apresentar os caminhos necessários para o Brasil evoluir em termos de sistema financeiro e suas facilidades decorrentes do novo modelo de atendimento para uma demanda cada dia mais conectada.

As escolhas que os grandes bancos devem proceder sobre seu futuro posicionamento e o caminho que vão se envolver com outras partes externas devem determinar os recursos e dispêndio de energia para a manutenção da base de clientes e ampliação com novos segmentos de mercados. Com várias formas confiáveis de jogar e posturas estratégicas, não há abordagem de tamanho único para todos. Independentemente RC: 61199

Link de acesso: https://www.nucleodoconhecimento.com.br/contabilidade/mercado-financeiro 
de como a paisagem evolui, no entanto, bancos que obtiverem sucesso terão certas características comuns:

- Eles serão verdadeiramente centrados no cliente, usando uma visão profunda sobre o que os clientes realmente valorizam o desenvolvimento de produtos, o design de canais e experiência e preço;

- Eles serão ágeis e capazes de se adaptar a um ambiente em rápida mudança, com mecanismos para rastrear o que está acontecendo no mercado, avaliar as mudanças nas preferências dos clientes e reorientar os negócios para permanecer relevante;

- Eles serão excelentes na análise de dados, não apenas como base para tomada de decisão e projeto de proposição, mas incorporado em produtos para fornecer experiências sob medida, gerenciamento de risco em tempo real e precificação dinâmica;

- Eles serão habilidosos em trabalhar com outras empresas em um complexo ecossistema de parcerias e mercados, para proporcionar ofertas que integram os melhores serviços disponíveis no mercado para seus clientes;

- Eles serão excelentes na construção de tecnologia excitante e segura soluções que permitem que novas funcionalidades sejam desenvolvidas e implantadas rapidamente, e permitir uma integração fácil e segura com os sistemas externos.

O desenvolvimento desses atributos não será fácil para muitas organizações, com mudanças bastante radicais necessárias às suas habilidades, cultura e de trabalho; bem como às plataformas tecnológicas que sustentam suas ofertas digitais.

Uma das formas que o artigo descortina para facilitar a migração à essa nova realidade encontra-se apoio no conceito de Open Banking em conjunto com os recursos a desenvolver, como incorporar o foco no cliente e ampliar o valor adicionando aos produtos. Ainda, como organizar e alavancar recursos externos e capacidades (seja através de parceria ou aquisição). 
Projetos importantes relacionados à tecnologia, incluindo como construir e incorporar capacidades de diferenciação analítica de dados e inteligência artificial, como arquitetar e desenvolver plataformas modulares que facilitam a integração e implantação de novas funcionalidades inovadoras serão requisitos básicos para o sucesso em ambiente extremamente competitivo. Assim os grandes bancos nacionais precisam ter clareza sobre como gerenciarão o cyberspace em termos de segurança da informação, manutenção da base de clientes, sistemas operacionais e dados seguros, e como eles protegerão os clientes contra fraudes.

Embora o futuro seja imprevisível, há muitas medidas práticas que os bancos podem adotar imediatamente. Abaixo, segue a figura 3, um esquema proposto por Reincheld (2018) e Rawson et. al. (2013) sobre como implementar proposta de inovação.

Figura 3 - Passo a passo de um programa de gestão e inovação em CX.

\begin{tabular}{|c|c|c|c|c|c|}
\hline & $\begin{array}{c}\text { Preparando as } \\
\text { bases - Estratégia } \\
\text { de CX }\end{array}$ & $\begin{array}{l}\text { minando as } \\
\text { métricas }\end{array}$ & $\mathbf{p}$ & $\begin{array}{c}\text { Cultura e } \\
\text { Engajamento }\end{array}$ & $\begin{array}{c}\text { Suporte analítico } \\
\text { e automação }\end{array}$ \\
\hline Jbjetivos & $\begin{array}{l}\text { - Desenvolver visão } \\
\text { de } C X \\
\text { compartilhada }\end{array}$ & $\begin{array}{l}\text { Ter o melhor } \\
\text { conjunto de } \\
\text { métricas }\end{array}$ & $\begin{array}{l}\text { - Melhorar a } \\
\text { experiência }\end{array}$ & $\begin{array}{l}\text { - Organização } \\
\text { Centrada no } \\
\text { Cliente }\end{array}$ & - Análises 2.0 \\
\hline Atividades & $\begin{array}{l}\text { - Compromisso da } \\
\text { liderança } \\
\text { - ROI de CXM } \\
\text { - Benchmarking } \\
\text { competitivo } \\
\text { - Ideal Customer } \\
\text { Experience } \\
\text { - Análise das } \\
\text { Lacunas }\end{array}$ & $\begin{array}{l}\text { - Estudos das métricas } \\
\text { mais adequadas } \\
\text { - Definição de } \\
\text { métricas } \\
\text { - Integração de } \\
\text { Feedbacks }\end{array}$ & $\begin{array}{l}\text { - Workshops de } \\
\text { ativação } \\
\text { - Identificação de } \\
\text { melhores práticas } \\
\text { - Otimização de } \\
\text { procedimentos } \\
\text { - Inovação e CX }\end{array}$ & $\begin{array}{l}\text { - CX como } \\
\text { competência central } \\
\text { - Gestão de } \\
\text { treinamentos } \\
\text { - Campanhas internas } \\
\text { - Incentivos }\end{array}$ & $\begin{array}{l}\text { - Automação } \\
\text { - Big data } \\
\text { - CX Preditivo } \\
\text { - Análises avançadas }\end{array}$ \\
\hline Entregas & - Estratégia de CXM & $\begin{array}{l}\text { - Competência em } \\
\text { Gestão das métricas }\end{array}$ & $\begin{array}{l}\text { - Sistema de Close the } \\
\text { Loop }\end{array}$ & $\begin{array}{l}\text { - Cultura e } \\
\text { Engajamento }\end{array}$ & $\begin{array}{l}\text { - Extrair todo o } \\
\text { potencial de } C X\end{array}$ \\
\hline
\end{tabular}

Fonte: Adaptado de REINCHELD (2018); RAWSON et. al. (2013).

No que tange as possibilidades operacionais, segue modelo proposto pela equipe de consultoria da Price Waterhous Coopers, adaptado pelos autores, na busca de transformar o ambiente interno de um grande banco ampliando suas fronteiras de atuação de acordo com a figura 4: 
Figura 4 - Modelo de Open Banking.

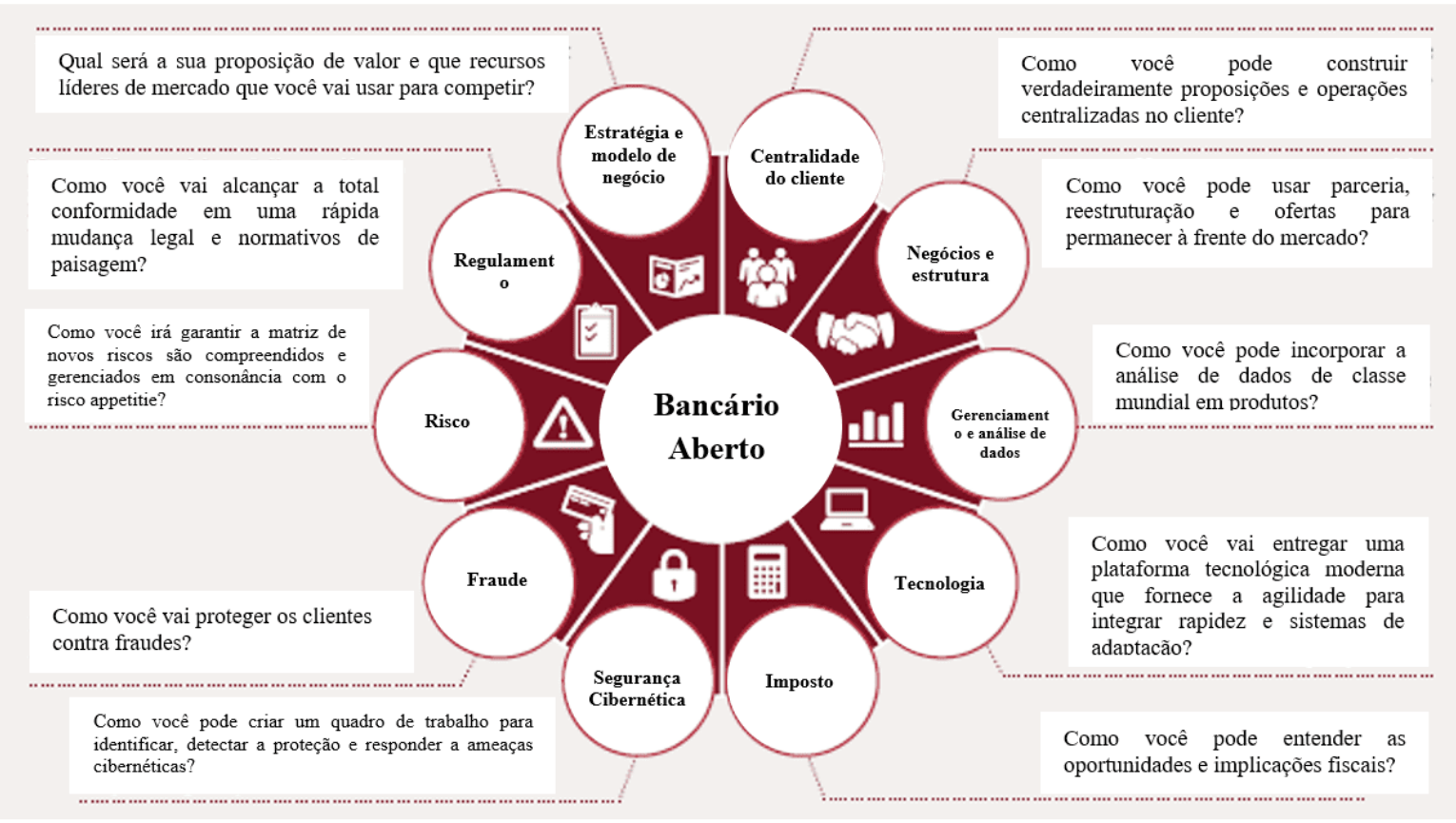

Fonte: PRICE WATERHOUSE COOPERS INTERNAL REPORT (2018).

\section{REFERÊNCIAS}

ALECRIM, Emerson. O que é Fintech? Info Wester, 31 mar. 2016. Disponível em: https://www.infowester.com/fintech.php. Acesso em: 05 abr. 2019.

AMORIM, Lucas. País das cópias virou polo de inovação - e isso muda o mundo. Revista Exame, 30 nov. 2017. Disponível em: https://exame.abril.com.br/revistaexame/e-hora-de-copiar-a-china/. Acesso em: 25 mar. 2019.

BANCO CENTRAL DO BRASIL (BACEN). Relatório de economia bancária: 2018. Brasília, DF: Banco Central do Brasil, 2018.

BANCO GOLDMAN SACHS. Future of finance: Fintech's Brazil moment. New York: Goldman Sachs Global Investment Research, 2017.

BERMUDEZ, Jocelyn. China may soon surpass U.S. in the Global Education Technology Market. Ed Tech Times, 7 oct., 2016. Disponível em: 
https://edtechtimes.com/2016/10/07/china-may-soon-surpass-u-s-in-the-globaleducation-technology-race/. Acesso em: 10 mar. 2019.

BUCHAK, G., MATVOS, G. PISKORSKI, T. SERU, A. FinTech, regulatory arbitrage, and the rise of shadow banks. NBER Working Papers, n. 23288, mar. 2017.

CAMBRIDGE Centre for Alternative Finance. Sustaining momentum: the Second European Alternative Finance Industry Report, sep. 2016.

CAMBRIDGE Centre for Alternative Finance and Chicago-Booth Polsk. Center Breaking new ground: the Americas Alternative Finance Industry Report, April. (2016):

CAMBRIDGE Centre for Alternative Finance and Nesta. Pushing boundaries: the 2015 UK Alternative Finance Industry Report, mar. 2016.

CAMBRIDGE Centre for Alternative Finance and Nesta. Pushing boundaries: the 2015 UK Alternative Finance Industry Report, mar. 2016.

CAMBRIDGE Centre for Alternative Finance and University of Sydney Business School. Harnessing potential: the Asia-Pacific and China alternative finance benchmarking report, mar., 2016.

CARNEY, M. The promise of FinTech: something new under the sun? Speech at the Deutsche Bundesbank G20. Conference on Digitising finance, financial inclusion and financial literacy, Wiesbaden, 25 jan., 2017.

COMMITTEE on Payments and Market Infrastructures. Distributed ledger in payment, clearing and settlement: an analytical framework. Feb., 2017.

DAVIS, K.; MURPHY, J. Peer-to-peer lending structures, risks and regulation. The Finsia Journal of Applied Finance, v. 3, 2016, p. 37-44.

DE ROURE, C.; PELIZZON, L.; TASCA, P. How does P2P lending fit into the consumer credit market? Deutsche Bundesbank Discussion Papers, n. 30, 2016.

RC: 61199

Link de acesso: https://www.nucleodoconhecimento.com.br/contabilidade/mercado-financeiro 
DEER, L.; MI, J.; YUXIN, Y. The rise of peer-to-peer lending in China: an overview and survey case study. Association of Chartered Certified Accountants, 2015.

DEMYANYK, Y.; KOLLINER, D. Peer-to-peer lending is poised to grow. Federal Reserve Bank of Cleveland, aug. 2014.

DIXON, Matthew; FREEMAN, Karen; TOMAN, Nicholas. Customer effort ratio: stop trying to delight your customers. Harvard Business Review, v. 88, n. 7/8, jul.-aug., 2010, p. 116-122. Disponível em: https://hbr.org/2010/07/stop-trying-to-delight-yourcustomers. Acesso em: 18 mar. 2019.

GIANCOTTI, James. Beijing: one of the top startup ecosystems in Asia. Forbes, 09 aug. 2016. Disponível em: https://www.forbes.com/sites/jamesgiancotti/2016/08/09/beijing-one-of-the-topstartup-ecosystems-in-asia/\#6203cdc125cb. Acesso em: 10 abr. 2019.

GIL, Antônio Carlos. Como elaborar projetos de pesquisa. 5. ed. São Paulo: Atlas, 2010.

IN FINTECH, China shows the way. The Economist, 25 feb. 2017. Disponível em: https://www.economist.com/finance-and-economics/2017/02/25/in-fintech-chinashows-the-way. Acesso em: 22 mar. 2019.

INCENTIVO ao empreendedorismo: um negócio da China. Isto é dinheiro, n. 1116, 22 mai. 2017. Disponível em: https://www.istoedinheiro.com.br/incentivo-aoempreendedorismo-um-negocio-da-china/. Acesso em: 16 abr. 2019.

INTERNATIONAL Association of Insurance Supervisors (IAIS). FinTech developments in the insurance industry, 21 fev. 2017.

INTERNATIONAL Organization of Securities Commissions. Research Report on Financial Technologies (FinTech), feb. 2017.

JENIK, I.; LYMAN, T.; NAVA, A. Crowdfunding and financial inclusion. [S. I.]: Working Paper, 2017.

$\mathrm{RC}: 61199$

Link de acesso: https://www.nucleodoconhecimento.com.br/contabilidade/mercado-financeiro 
JOURDAN, Adam. Digital doctors: China sees tech cure for healthcare woes. Reuters, 14 oct., 2014. Disponível em: https://uk.reuters.com/article/uk-china-healthcaredigital/digital-doctors-china-sees-tech-cure-for-healthcare-woesidUKKCNOI32OX20141014. Acesso em: 11 abr. 2019.

KEININGHAM, T. L.; COOIL, B.; AKSOY, L.; ANDREASSEN, T. W.; WEINER, J. (2007). The value of different customer satisfaction and loyalty metrics in predicting customer retention, recommendation, and share-of-wallet. Managing service quality: an international Journal, v. 17, n. 4, p. 361-384. Disponível em: http://www2.owen.vanderbilt.edu/bruce.cooil/documents/publications/msq2007.pdf. Acesso em: 07 abr. 2019.

KIRBY, E.; WORNER, E. Crowdfunding: an infant industry growing fast. International Organization of Securities Commissions, mar., 2014.

MAGIDS, Scott; ZORFAS, Alan; LEEMON, Daniel. The new science of customer emotions. Harvard Business Review, v. 76, nov., 2015, p. 66-74. Disponível em: https://hbr.org/2015/11/the-new-science-of-customer-emotions. Acesso em: 10 mar. 2019.

MARKEY, Rob; REICHHELD, Fred; DULLWEBER, Andreas. Closing the customer feedback loop. Harvard Business Review, v. 87, n. 12, dec., 2009, p. 43-47. Disponível em: https://hbr.org/2009/12/closing-the-customer-feedback-loop. Acesso em: 04 mar. 2019.

MILNE, A.; PARBOTEEAH, P. The business models and economics of peer-to-peer lending. European Credit Research Institute, 2016.

MORESI, Eduardo (org.). Pró-reitoria de Pós-graduação (org.). Metodologia da pesquisa. Brasília: Universidade Católica de Brasília, 2003. Disponível em: http://www.inf.ufes.br/ falbo/files/MetodologiaPesquisa-Moresi2003.pdf. Acesso em: 27 jun. 2014. 
MORSE, A. Peer-to-peer crowdfunding: information and the potential for disruption in consumer lending. NBER Working Papers, n. 20899, jan.-may., 2015.

MOULES, J. Santander in peer-to-peer pact as alternative finance makes gains. Financial Times, 17 jun., 2014.

ORTUS round table: the future of China's innovation hubs. Ortus Club, 13 dec. 2017. Disponível em: http://ortus.club/uncategorized/nova-china-innovation/. Acesso em: 11 abr. 2019.

POWELL, Brian. Agritech startups in 2016: saw less investment but more diversification. Yostartups.com, 8 mar. 2017. Disponível em: https://yostartups.com/agritech-2016-witnessed-less-investment-diversification/. Acesso em: 03 mar. 2019.

PRICE Water House Coopers. Peer pressure: how peer-to-peer lending platforms are transforming the consumer lending industry, fev., 2015.

RATINECAS, Paulo. Ecossistema empreendedor da China. 6 mar. 2019. Disponível em: $\quad$ https://www.slideshare.net/ratinecas/ecossistema-empreendedor-da-chinaestudo-startse. Acesso em: 28 mar. 2019.

RAU, R. Law, trust, and the development of crowdfunding. University of Cambridge Woking Paper, 2017.

RAWSON, Alex; DUNCAN, Ewan; JONES, Conor. The truth about customer experience. Harvard Business Review, v. 91, n. 9, set., 2013, p. 90-98. Disponível em: https://hbr.org/2013/09/the-truth-about-customer-experience. Acesso em: 04 mar. 2019.

REICHHELD, F. F. The one number you need to grow. Harvard business review, v. 81 , n. 12 , dec., 2003, p. 46-55.

REICHHELD, F. F.; SASSER JR., W. E. Zero defections: quality comes to services. Harvard Business Review, v. 68, n. 5, sep.-oct., 1990, p. 105-111. RC: 61199

Link de acesso: https://www.nucleodoconhecimento.com.br/contabilidade/mercado-financeiro 
SAKAMOTO, Camila. Shenzhen: a cidade da inovação. China Link Trading, 02 mai. 2017. Disponível em: http://www.chinalinktrading.com/blog/shenzhen-cidade-dainovacao/. Acesso em: 03 abr. 2019.

TOP 6 fast growing Tech Industries in China: artificial intelligence \& healthtech (part 2/3). Thexnode.com, 20 dec., 2016. Disponível em: http://www.thexnode.com/blog/top-6-fast-growing-tech-industries-in-china-artificialintelligence. Acesso em: 13 mar. 2019.

TOP 6 fast growning Tech Industries in China: Fintech \& Edtech (part 1/3). Thexnode.com, 30 nov. 2016. Disponível em: http://www.thexnode.com/blog/top-6fast-growing-tech-industries-in-china-fintech-edtech-part-1-3. Acesso em: 13 mar. 2019.

UNESP. Modelos de recuperação da informação. 23 ago. 2018. Disponível em: https://www.marilia.unesp.br/Home/Instituicao/Docentes/EdbertoFerneda/ri04--modelosri.pdf. Acesso em: 05 abr. 2019.

USUÁRIOS de internet na China ultrapassam os 649 milhões em 2014. O Globo Economia, 03 fev. $2015 . \quad$ Disponível em: https://oglobo.globo.com/economia/tecnologia/usuarios-de-internet-na-chinaultrapassam-os-649-milhoes-em-2014-15231412. Acesso em: 03 abr. 2019.

VALENTE, Jonas. Relatório aponta Brasil como quarto país em número de usuários de internet. Agência Brasil, 03 out. 2017. Disponível em: http://agenciabrasil.ebc.com.br/geral/noticia/2017-10/relatorio-aponta-brasil-comoquarto-pais-em-numero-de-usuarios-de-internet. Acesso em: 02 abr. 2019.

VERGARA, Sylvia Constant. Projetos e relatórios de pesquisa em administração. 13. ed. São Paulo: Atlas, 2011.

WANG, Yue. Will the future of artificial intelligence look Chinese? Forbes, 6 nov. 2017. Disponível em: https://www.forbes.com/sites/ywang/2017/11/06/will-the-future-ofartificial-intelligence-look-chinese/\#48cac8f77fdc. Acesso em: 05 abr. 2019.

RC: 61199

Link de acesso: https://www.nucleodoconhecimento.com.br/contabilidade/mercado-financeiro 
XIANG, Nina. China is quietly catching up on healthcare technology. China Money Network, $31 \quad$ mar. $2017 . \quad$ Disponível em: https://www.chinamoneynetwork.com/2017/03/31/china-is-quietly-catching-up-onhealthcare-technology. Acesso em: 15 mar. 2019.

XIANG, Nina. Here are China's top 10 al companies challenging US tech leadership. China Money Network, 07 mar. 2017. Disponível em: https://www.chinamoneynetwork.com/2017/03/07/here-are-chinas-top-10-aicompanies-challenging-us-tech-leadership. Acesso em: 15 mar. 2019.

YEUNG, Edith. China internet trends 2017. Disponível em: https://pt.slideshare.net/EdithYeung/china-internet-report-2017-by-edith-yeung. Acesso em: 25 mar. 2019.

\section{APÊNDICE - REFERÊNCIAS DE NOTA DE RODAPÉ}

3. FinTechs - empresas provedoras de serviços financeiros com processos inteiramente baseados em tecnologia, dentre os quais destacam-se: pagamentos, empréstimos, seguros e investimentos.

4. Startups - modelo de negócios desenvolvido por empresas recentes, relacionados, em geral, à inovação e tecnologia.

5. Spreads - diferença entre preço de compra e venda, ou seja, a sobretaxa cobrada numa operação financeira.

6. Equity research - segmento dentro do mercado financeiro responsável por estudar e analisar detalhadamente as informações de uma empresa e do seu negócio como um todo, objetivando oportunidades de investimentos.

7. Crowdfunders - modalidade de investimento onde várias pessoas podem investir pequenas quantias de dinheiro num determinado negócio, geralmente via internet, a fim de dar vida à uma ideia. 
8. $P 2 P$ - do inglês peer-to-peer, o qual significa par-a-par, é um formato de rede de computadores com funções descentralizadas das funções convencionais de rede, onde o computador de cada usuário conectado acaba por realizar funções de servidor e de cliente ao mesmo tempo.

9. Herfindahl Hirschman - é uma medida comum de concentração de mercado, utilizada para determinar a competitividade do mesmo. É calculado ao se enquadrar a participação e mercado de cada empresa num ambiente competitivo. Pode variar de zero a 10.000. O Departamento de Justiça dos EUA o utiliza para avaliar possíveis problemas de fusão, além de reguladores identificarem a partir do mesmo se eventual setor pode ser considerado competitivo ou operando sob um determinado monopólio.

10. Insper - é uma instituição de ensino superior brasileira que atua nas áreas de negócios, economia, direito, engenharia mecânica, engenharia mecatrônica e engenharia da computação.

11. IAIS - International Association of Insurance Supervisors.

12. CAGR - Compound Annual Growth Rate.

13. Big Data - é a análise e a interpretação de grandes volumes de dados de grande variedade. Para isso são necessárias soluções específicas que permitam a profissionais de $\mathrm{TI}$ trabalhar com informações não-estruturadas a uma grande velocidade.

Enviado: Setembro, 2020.

Aprovado: Outubro, 2020. 